\title{
Predicting Employee Attitudes to Workplace Diversity from Personality, Values, and Cognitive Ability
}

Jeromy Anglim, Victor Sojo, Linda J. Ashford, Alexander Newman, Andrew Marty ${ }^{1}$

\begin{abstract}
The current study assessed the predictive validity of broad and narrow measures of personality, values, and cognitive ability on employee attitudes to workplace diversity. Australian working adults $(N=$ $731 ; 66 \%$ female; mean age $=43, S D=12$ ) completed the 200-item HEXACO Personality Inventory, Schwartz's Portrait Values Questionnaire, ACER measures of numeric, verbal, and abstract reasoning ability, the Attitudes Toward Diversity Scale, and four scales measuring prejudice towards female workers, ethnic workers, older workers, and workers with a disability. Results showed that Honesty-Humility, Extraversion, Openness, and cognitive ability (especially verbal) predicted more positive attitudes to workplace diversity. Valuing power, security,
\end{abstract}

${ }^{1}$ Citation: Anglim, J., Sojo, V., Ashford, L. J., Newman, A., \& Marty, A. (2019). Predicting Employee Attitudes to Workplace Diversity from Personality, Values, and Cognitive Ability. Journal of Research in Personality, 83, 103865. https://doi.org/10.1016/j.jrp.2019.103865

Check with publisher for updated page numbers.

Data Access: Data, data analysis scripts, supplementary materials, and item-level information is provided at https://osf.io/xdfq8 The study and analysis plan was not pre-registered.

Author Affiliations: Jeromy Anglim, School of Psychology, Deakin University, Geelong, Australia; Victor Sojo, Centre for Workplace Leadership, The University of Melbourne, Melbourne, Victoria, Australia; Linda J. Ashford, School of Psychology, Deakin University, Geelong, Australia; Alexander Newman, Deakin Business School, Deakin University, Geelong, Australia; Andrew Marty, SACS Consulting, 101 Collins Street, Melbourne, Victoria, Australia, 3000. Correspondence concerning this article should be addressed to Jeromy Anglim, School of Psychology, Deakin University, Locked Bag 20000, Geelong, 3220 Australia. Email: jeromy.anglim@deakin.edu.au

Author Contributions: JA contributed to study design and led the writeup and data analysis for the report; VS contributed to study design, framing of the paper, and writing the report; LA and AN contributed to writing the report; AM led the study design and the data collection, and contributed to the write-up of the paper.

Declaration of Interests: The authors declare the following financial interests/personal relationships which may be considered as potential competing interests: The fifth author uses the described HEXACO, Values, and cognitive ability measures as part of a psychometrics testing business. 
and tradition more, and valuing universalism less was associated with more negative attitudes to workplace diversity. intelligence

Keywords: attitudes to diversity, HEXACO, personality, values,

\section{Introduction}

Workplace diversity has become an increasingly important topic for both organizational researchers and practitioners (for reviews, see Ashkanasy, Härtel, \& Daus, 2002; Guillaume, Dawson, Woods, Sacramento, \& West, 2013; Harrison \& Klein, 2007; Jonsen, Maznevski, $\&$ Schneider, 2011). Female workforce participation continues to increase, and in many countries, the workforce is becoming more diverse across a range of dimensions including race, ethnicity, age, and inclusion of people with disability (Byars-Winston, Fouad, \& Wen, 2015). Globalization and the resultant movement of labour across national boundaries has led to increasing interest amongst researchers and practitioners alike as to how to manage diversity (Ashkanasy et al., 2002; Singh, Winkel, \& Selvarajan, 2013). There is also a growing awareness of the prevalence of overt and subtle forms of discrimination and the negative consequences that flow from this (Colella, Hebl, \& King, 2017; Jones, Peddie, Gilrane, King, \& Gray, 2016). Furthermore, legal obligations, ethical priorities, reputational concerns, and a desire to achieve the performance benefits of a diverse workforce (Ashkanasy et al., 2002; Jehn, Northcraft, \& Neale, 1999) have motivated researchers to study, and organizations to implement, initiatives aimed at better fostering diversity and inclusion (Avery \& McKay, 2006; Newman, Nielsen, Smyth, Hirst, \& Kennedy, 2018; Pugh, Dietz, Brief, \& Wiley, 2008; Sojo, Wood, Wood, \& Wheeler, 2016). This movement has focused attention on methods of selection, training, and employee organization that might support a diverse workforce (Guillaume et al., 2014; Jehn et al., 1999; Pendry, Driscoll, \& Field, 2007; Stratemeyer et al., 2018; Strauss, Connerley, \& Ammermann, 2003).

For organizations to achieve their goals around fostering diversity, they need to understand the cross-national, macro-economic, social, organizational, team-level, and personal factors that influence workers' attitudes towards workplace diversity (Ashkanasy et al., 2002; Burkard, Boticki, \& Madson, 2002; De Meuse \& Hostager, 2001; Ely \& Thomas, 2001; Montei, Adams, \& Eggers, 1996). In the current study, we focus on individual-level predictors of attitudes towards workplace diversity. More specifically, we evaluate three types of individual differences, namely personality traits, values and cognitive abilities in relation to both broad negative attitudes towards workplace diversity, as well as specific attitudes towards female, ethnic minority, individuals living with a disability, and older workers. This study also provides new insights about the predictive value of broad and narrow facets of the individual differences evaluated, while remedying some of the limitations of previous research in this area.

\subsection{Attitudes towards Workplace Diversity}


Negative employee attitudes to workplace diversity are multifaceted (De Meuse \& Hostager, 2001) and include both workplace prejudice and the rejection of many initiatives used to promote workplace diversity. Outside the workplace, prejudice including sexism and racism, is any unjustified belief that a particular social group is inferior to another (Duckitt, 2001; Ekehammar, Akrami, Gylje, \& Zakrisson, 2004; Milliken $\&$ Martins, 1996), and has been described as a general motivated cognitive style where the specific object of derision is of secondary importance (Allport, 1954; Roets \& van Hiel, 2011). Workplace prejudice is typified by unreasonable beliefs that workers belonging to particular social groups are less capable, less motivated, or cause more problems in the workplace. Such beliefs can be general, or may be concerned with specific roles such as those involving leadership or technical skills, or specific social groups such as women or ethnic minorities. The prejudiced belief system described above is based, in part, on stereotypes about these stigmatized groups' purported inherent attributes, and how poorly these attributes are thought to match the behaviors required in specific roles or the workplace in general (Eagly \& Karau, 2002; Heilman \& Caleo, 2018).

While prejudice, discrimination, and abuse are distinct, they often co-occur (Goldman, Gutek, Stein, \& Lewis, 2006). Prejudice has been consistently linked to workplace discrimination and mistreatment towards women and members of minority groups (Colella et al., 2017; Fiske, 1998; Fiske \& Stevens, 1993; Jones et al., 2016; Roberts, Sojo, \& Grant, 2019). Discrimination leads to reduced occupational opportunities and well-being. It also helps to reinforce the view that stigmatized groups are not a good fit for work in general, specific occupations, and positions of leadership (Koenig \& Eagly, 2014; Schein, Mueller, Lituchy, \& Liu, 1996). In turn, this situation increases the likelihood that stigmatized groups will experience backlash when they enter those positions (Rudman, MossRacusin, Phelan, \& Nauts, 2012; Sojo, Wood, \& Genat, 2016), potentially perpetuating a vicious cycle.

Beyond prejudice, negative attitudes towards workplace diversity often involve workers holding a number of inter-connected beliefs associated with the political right, conservatism, and individualism. These beliefs can be seen expressed by right-leaning politicians, in newspapers, and by commentators who identify with classical liberalism such as Jordan Peterson (Peterson, 2018). People with negative attitudes to workplace diversity may be particularly sensitive to initiatives related to affirmative action including opportunity enhancement initiatives, quotas, targets, and using social category membership to inform pay, selection, promotion, and retention decisions (Harrison, Kravitz, Mayer, Leslie, \& Lev-Arey, 2006). They may believe that diversity-related policies are leading to reversediscrimination and resulting in employees from less qualified minority groups being promoted or hired (Wiersema \& Mors, 2016). They may be more likely to see historical differences in workplace outcomes of different social groups (e.g., the gender pay gap, gendered occupations, etc.) as 
natural, and resulting largely from (a) individual choices, (b) differences in underlying abilities, interests, and dispositions, and (c) meritocratic decision processes (Jones, 2017). In the context of workplace harassment, they may downplay the abuse and place greater emphasis on concerns about false accusations (De Judicibus \& McCabe, 2001; Ullman, 2010). They may see diversity of competency rather than demographic diversity as the key to organizational performance benefits. They also often dispute the science and implementation of unconscious bias training in organizations. They may raise concerns about political correctness stifling freedom of speech when it comes to discussing diversity-related issues. Some may also seek to defend the rights of workers to express prejudiced views towards various minority groups including homosexuals, transgender people, and religious minorities without this affecting their employment (Kitrosser, 2016).

In contrast, positive attitudes to workplace diversity often aligns with the political left. People with positive attitudes often emphasize the benefits of diversity and inclusion and the importance of creating a respectful and tolerant workplace. They may be particularly aware of the role of historical and current social structures and policies that have limited the participation of various social groups in the workplace (Dick \& Nadin, 2006). They are more inclined to view unequal outcomes across social groups to be the result of workplace discrimination, including both conscious and unconscious biases, as well as broader social, cultural, and economic structures (Fine \& Sojo, 2019). They are also keen to redress past wrongs. They are typically wary of making claims about group differences that might perpetuate the adverse treatment of minorities. They may be more inclined to see group differences in work-relevant characteristics as caused by social factors as opposed to reflecting enduring biological differences (Fine, 2005). They may also be more willing to believe that social groups are equally competent or that the increasing inclusion of minorities will yield performance benefits for teams and organizations.

\subsection{Personality, Values, and Cognitive Ability}

Individual differences are widely recognized as important predictors of workplace behaviors, attitudes, and outcomes (Hough \& Connelly, 2013). In the current study, we focus on three types of individual differences, namely personality traits, values and cognitive ability, which have been recognized as relevant predictors of workplace behaviors and are routinely used in personnel selection processes.

Personality traits represent relatively stable tendencies in thinking, feeling, and behaving. Personality researchers generally conceptualize traits in a hierarchy where a set of broad domains, such as the Big Fiveneuroticism, Extraversion, Openness, Conscientiousness, and Agreeableness - and alternatives like the six HEXACO factors, are each decomposed into several narrow traits or facets (Anglim \& Grant, 2014, 2016; Anglim \& O’Connor, 2019; Ashton, Lee, Goldberg, \& De Vries, 2009; Costa \& McCrae, 1992; Srivastava, 2013). The six factor HEXACO 
model has emerged as an important extension and alternative to the Big Five. Lexical studies in a range of cultures have provided support for the six-factor model (i.e., an acronym for Honesty-Humility, Emotionality, Extraversion, Agreeableness, Conscientiousness, and Openness; (Ashton et al., 2004; De Raad et al., 2014; Saucier, 2009). The HEXACO model reconfigures variance associated with Big Five Agreeableness and Neuroticism into Honesty-Humility, Emotionality, and HEXACO Agreeableness (see Lee \& Ashton, 2004). In particular, HEXACO Agreeableness emphasizes low levels of anger and Emotionality includes facets of dependence and sentimentality which are less aligned with the negative affect of neuroticism (for a review, see Ashton, Lee, \& De Vries, 2014). Honesty-Humility also has very strong negative correlations with the Dark Triad (Hodson et al., 2018; Lee \& Ashton, 2014). The six domains have also been decomposed into four facets per domain along with the interstitial facet of altruism. While the Big Five remains the most established framework, the HEXACO model has become increasingly popular in industrial and organizational psychology (Anglim, Morse, De Vries, MacCann, \& Marty, 2017; Hough \& Connelly, 2013; McAbee, Casillas, Way, \& Guo, 2019), due in part to the ability of HonestyHumility to incrementally predict a range of workplace deviance behaviors (e.g., De Vries \& Van Gelder, 2015; Marcus, Lee, \& Ashton, 2007; Oh, Lee, Ashton, \& De Vries, 2011; Pletzer, Bentvelzen, Oostrom, \& De Vries, 2019). In the current study, we adopt the HEXACO framework, in part, because of the potential for Honesty-Humility to provide increased predictive capacity of attitudes towards workplace diversity and prejudice towards women and minority groups at work.

Personal values are broad evaluative criteria that assist people to prioritize goals and set an agenda for what is important in their life (Schwartz, 1992). While various taxonomies have been proposed, arguably the most established framework is that proposed by Schwartz (Schwartz, 1992; Schwartz et al., 2012). The framework consists of ten basic values arranged in a circumplex, which in clockwise order are labelled selfdirection, stimulation, hedonism, achievement, power, security, tradition, conformity, benevolence, and universalism. The ten values can be represented by two broad dimensions of conservatism (conformity, tradition, security) versus Openness (self-direction and stimulation) and self-enhancement (hedonism, power, achievement) versus selftranscendence (universalism and benevolence).

Cognitive ability is typically conceptualized as a general higherorder construct - the general intelligence factor (Schneider \& McGrew, 2012). This g-factor is a robust result of the first principal component that manifests from the correlations of a broad battery of ability tests. While the dominant taxonomy of intelligence is the Cattell-Horn-Caroll model (Schneider \& McGrew, 2012), in the current study, we focus on overall intelligence and three narrow abilities that are popular in employee selection settings: numeric, verbal, and abstract reasoning ability. 
In order to develop parsimonious models of the effect of individual differences, it is important to acknowledge the correlations between values, personality, and cognitive ability. In particular, several studies have found correlations between personality and Schwartz's personal values both in relation to the Big Five (Parks-Leduc, Feldman, \& Bardi, 2015) and HEXACO personality models (Anglim, Knowles, Dunlop, \& Marty, 2017; Lee, Ashton, Ogunfowora, Bourdage, \& Shin, 2010b). Anglim, Knowles, et al. (2017) found that Honesty-Humility had a strong negative correlation with self-enhancement (versus self-transcendence). Honesty-Humility (Lee et al., 2013) and the value of self-enhancement (Duckitt, 2001) are also closely related to social dominance orientation. Openness also correlates negatively with the value of conservatism in both Big Five (Parks-Leduc et al., 2015) and HEXACO models (Anglim, Knowles, et al., 2017). Meta-analytic results also indicate modest correlations between Openness and cognitive ability (Ackerman \& Heggestad, 1997). Some research suggests that much of the correlation with Openness reflects its emphasis on self-rated intelligence, and that more pure forms of Openness are mainly related to verbal ability (Deyoung, Quilty, Peterson, \& Gray, 2014).

Another feature shared across personality, values, and cognitive ability is that traits can be arranged hierarchically. Broad traits explain covariation in, and are defined by, a set of narrower traits. Personality can be represented by domains and facets, values by broad and basic levels, and intelligence by a general factor and narrow abilities. Researchers have debated the relative importance of broad and narrow characteristics, particularly in the personality and cognitive ability domains (Anglim \& Grant, 2014; Anglim \& O'Connor, 2019; Ashton, 1998; Ashton, Paunonen, \& Lee, 2014; Christiansen \& Robie, 2011; O’Neill, Paunonen, Christiansen, \& Tett, 2013; Ones \& Viswesvaran, 1996; Paunonen \& Ashton, 2001; Salgado, Moscoso, \& Berges, 2013). In the current research, we explore the association of broad and narrow operationalizations of personality traits, values and cognitive abilities in relation to negative attitudes to workplace diversity.

\subsection{Individual Differences and Attitudes to Workplace Diversity}

Because only a few studies have examined how individual differences predict attitudes to workplace diversity (Strauss \& Connerley, 2003; Thompson, Brossart, Carlozzi, \& Miville, 2002), it is helpful to summarize research from the broader literature on social prejudice. In general, the research on the correlates of personality and values has highlighted two main classes of individual differences with general prejudice. First, low Openness and conservatism predict higher levels of prejudice. Second, low levels of Big Five Agreeableness and low levels of HEXACO Honesty-Humility are correlated with values related to selfenhancement, and both predict greater prejudice. For instance, Duckitt (2001) argued that the two broad values of conservatism and selfenhancement align closely with the concepts of right-wing authoritarianism 
and social dominance orientation, respectively. Duckitt (2001) proposed a dual-process theory which broadly suggests that social conformity and tough-mindedness lead to a set of world views and social attitudes that culminate in prejudicial views. Sibley and Duckitt (2008) suggested that prejudiced individuals are more likely to see their environment as socially competitive, valuing power and being conscious of situations where competition is a possibility, such as when there are limited resources.

Research on personality and general prejudice has typically used the Big Five framework and has found that Openness and Agreeableness are associated with lower levels of right-wing authoritarianism, social dominance orientation, and prejudice towards minorities (Duckitt, 2001; Ekehammar et al., 2004; Flynn, 2005; Hodson, Hogg, \& MacInnis, 2009; Sibley \& Duckitt, 2008; Sibley, Harding, Perry, Asbrock, \& Duckitt, 2010). A few studies have considered HEXACO and prejudice-related outcomes (Bergh \& Akrami, 2016; Lee, Ashton, Ogunfowora, Bourdage, \& Shin, 2010a; Liu, Ludeke, \& Zettler, 2017; Sibley et al., 2010). Bergh and Akrami (2016) found that Honesty-Humility was strongly correlated with generalized prejudice, whereas HEXACO Agreeableness showed limited correlations with prejudice.

Only a few studies have examined the predictive validity of complete hierarchical instruments of personality such as the NEO-PI-R in relation to attitudes to diversity (Thompson et al., 2002). While these studies have flagged narrow traits such as Openness to values, warmth, and tender-mindedness as potentially important, the multiplicities involved in facet-level analysis mean that sample sizes in existing studies of under 200 are insufficient for robust conclusions (for a methodological review of facet-level analysis, see Anglim \& Grant, 2014).

Research on cognitive ability has generally found a negative correlation between intelligence and general prejudice (Brandt \& Crawford, 2016; Onraet et al., 2015). One theory is that lower cognitive ability leads people to be more sensitive to threat, which in turn leads to more conservative political attitudes, which in turn lead to prejudice (Brandt \& Crawford, 2016). Another theory is that cognitive ability allows for greater tolerance of ambiguity and less need for closure, which may reduce reliance on negative stereotypes towards minorities. An alternative perspective is that cognitive ability leads to greater education and political liberalism, which in turn encourages more positive views towards some groups and more negative views towards others. For example, Brandt and Crawford (2016) found that the correlation between cognitive ability and prejudice varied based on the focal group, with negative correlations emerging for prejudice towards traditionally disadvantaged groups like blacks and Hispanics and positive correlations with prejudice towards groups associated more with right-wing conservatism, such as Christians, conservatives, and big business. While some research suggests verbal ability may be particularly relevant (Brandt \& Crawford, 2016), a previous meta-analysis did not find significant variation based on ability type 
(Onraet et al., 2015).

\subsection{The Current Study}

In summary, very little research has examined how individual differences in personality, values, and cognitive ability predict employee attitudes to workplace diversity (Strauss \& Connerley, 2003; Thompson et al., 2002). While research on general social prejudice has a long history in relation to personality (Adorno, Frenkel-Brunswik, Levinson, \& Stanford, 1950; Allport, 1954; Hodson \& Dhont, 2015), personal values (Lee et al., 2010a; Sibley et al., 2010), and cognitive ability (Brandt \& Crawford, 2016; Onraet et al., 2015), it is unclear how well this generalizes to the workplace. In particular, McAbee et al. (2019) reviewed the literature and highlighted the paucity of research examining the relationship between HEXACO personality and employee attitudes. Research has also rarely synthesized findings about the role of individual differences across personality, values, and cognitive ability. This integrated assessment is particularly important for practitioners considering using such information in selection, training, and professional development settings. Furthermore, while some research has examined predictors of attitudes to female and racial minority workers, less research has considered attitudes towards other marginalized workers such as older workers (Taylor \& Walker, 1998; Van Dalen, Henkens, \& Schippers, 2009), and workers with a disability (Ju, Roberts, \& Zhang, 2013; Kregel \& Tomiyasu, 1994). Finally, research has typically focused on broad traits and has rarely considered narrow traits measured by comprehensive hierarchical measures (Anglim \& Grant, 2014; Paunonen \& Jackson, 2000).

In order to address these gaps in the literature, the present study aimed to provide a comprehensive assessment of the predictive validity of broad and narrow measures of personality, values, and cognitive ability on employee attitudes to workplace diversity. To achieve this aim, a large database of job applicants who had completed measures of HEXACO personality, Schwartz personal values, and cognitive ability were invited to complete a confidential low-stakes survey where their attitudes to workplace diversity were measured. The study examined the relative predictive validity of broad and narrow characteristics represented by (a) 6 domains and 25 facets of HEXACO personality, (b) 2 broad dimensions and 10 basic values from Schwartz's personal values framework, and (c) intelligence and three specific cognitive abilities.

Based on the findings and theories from the general prejudice literature, our main hypotheses in relation to negative attitudes to workplace diversity are set out in Figure 1. This model combines personality traits, values, and abilities that are both intercorrelated and expected to have a common effect on negative attitudes to diversity. Specifically, we propose the following hypotheses:

Hypothesis 1. Honesty-Humility will predict less negative attitudes to workplace diversity.

Hypothesis 2. Valuing self-enhancement (valuing power more and 
universalism less) will predict more negative attitudes to workplace diversity.

Hypothesis 3. Openness to experience will predict less negative attitudes to workplace diversity.

Hypothesis 4. Valuing conservatism will predict more negative attitudes to workplace diversity.

Hypothesis 5. Cognitive ability will predict less negative attitudes to workplace diversity.

More generally, the research sought to obtain a detailed empirical assessment of how personality, values, and cognitive ability combine to predict negative attitudes to diversity. It also sought to assess the degree to which narrow representations of traits in these three domains provide incremental prediction. Research on the overlap of personality and values (Anglim, Knowles, et al., 2017; Parks-Leduc et al., 2015) suggests that much of the prediction of negative attitudes to diversity will be shared between personality and values. In contrast, cognitive ability should be a relatively independent predictor. Research on the incremental prediction of narrow traits suggests that modest but meaningful increases in prediction are to be expected (Anglim, Bozic, Little, \& Lievens, 2018; Anglim \& Grant, 2016; Anglim, Morse, et al., 2017; Anglim, Morse, Dunlop, Minbashian, \& Marty, 2019).

\section{Method}

\subsection{Participants and Procedure}

Participants were recruited from a database maintained by a consulting company that provides online psychometric testing services to client organizations. Client organizations used the online platform to assess job applicants for job vacancies at their organization. Job applicants completed measures of HEXACO personality, Schwartz Personal Values, and cognitive ability. Individuals who had completed these measures were emailed an invitation in mid-2017 to participate in a study looking at employees' attitudes to diversity in the workplace. The time difference between the baseline selection measures and the follow-up research study varied between six months and 3 years. Participants were informed that if they completed all items in the survey, they could win one of three travel vouchers valued at AUD \$3,000, \$2,000, and \$1,000. The survey included a range of additional items used by the consulting company for internal validation of their selection tools. Items used in the present research consisted of the Attitudes towards Diversity Scale and Domain Specific Diversity Items.

The final sample consisted of 731 participants (66\% female). Ages were broadly representative of the working adult population: 18 to 24 (5\%), 25 to $34(24 \%), 35$ to $44(25 \%), 45$ to $54(27 \%), 55$ to $64(16 \%)$ and 65 to $74(3 \%)$, with a mean of 43.0 years $(S D=12.0)$. Around half $(57 \%)$ of participants had children. Consistent with the Australian population, 70\% were born in Australia, and for 11\%, English was not their first language. 
The sample was slightly more educated than the Australian population: $1 \%$ did not complete high school, 5\% only completed high school, $21 \%$ had a pre-bachelor qualification, $44 \%$ had a bachelor's degree, $26 \%$ had a Master's degree, and $2 \%$ had a doctoral qualification. Most were currently employed (92\%) with 69\% in full-time, 15\% in part-time, and 9\% in casual roles, and most that were not employed had been employed in the last two years. Of the sample, 5\% reported having a disability, of which $82 \%$ described it as moderate or mild and $18 \%$ categorized it as profound or severe. This final sample was based on an initial sample of 750 participants, where 19 cases were removed due to signs of non-conscientious survey completion (i.e., two or more contradictory responses on diversity items that were direct opposites; high levels of consistent response choice selection across items; high levels of long sequences of the same response).

The sample size in the present study was determined by the response rate of the underlying database. We sought to obtain precise estimates of correlations between individual differences and attitudes to diversity. The obtained sample size provides the following power to identify given true correlations (alpha $=.05$ ): $80 \%$ power for .10 correlations, $90 \%$ power for .12correlations, and $99 \%$ power for .16 correlations. Given the emphasis on identifying patterns in correlations, the present sample size enabled suitably small standard errors for correlations. Specifically, the standard error was no larger than .036.

\subsection{Materials}

\subsubsection{Attitudes towards Diversity Scale}

Negative attitudes to workplace diversity were measured using an adapted version of the Attitudes Toward Diversity Scale (ATDS, Montei et al., 1996). The original version of the ATDS had 30 items and was designed to measure whether a worker had a positive or negative attitude to diversity in relation to three domains (a) coworkers who are a minority, (b) supervisors who are a minority, (c) hiring and promoting of minorities. In terms of social categories, items generally concerned race (i.e., Black, Hispanic, White) or gender (i.e., male, female), or used more general terms including "minority" (sometimes contrasted with White and sometimes with non-minority) or "prejudice" in general. Because our study was conducted in an Australian context, it was necessary to adapt the items. Australia has a different racial and ethnic profile to the United States, where the scale was originally developed. Australia has experienced many waves of immigration with $28.5 \%$ of the population born overseas as of 2016 . The top 10 countries of foreign birth were the United Kingdom, New Zealand, China, India, Philippines, Vietnam, Italy, South Africa, Malaysia, and Germany (Australian Bureau of Statistics, 2017). For further discussion of the workplace diversity context in Australia, see Härtel (2004). Items on the scale were adapted, changing items such as "minority" into "female or ethnic" and "Black" or "Hispanic" into "ethnic". The original study by Montei et al. (1996) did not present an exploratory factor analysis, but when we conducted exploratory factor analysis, we found that one factor 
explained the data well. The percentage variance explained of the first eight unrotated factors were 30.4, 6.9, 4.9, 4.3, 3.8, 3.6, 3.5, and 3.3. When two factors were extracted, items $2,4,6,7,8,17,21$, and 22 loaded most on a second factor. This seemed to detect a small distinction between workplace prejudice and positive attitudes to more proactive initiatives to address diversity. However, it also appeared to partially reflect a method-effect related to reversed-items. This second factor was highly correlated with the first factor $(r=-.50)$ and exhibited the same pattern of correlations with individual differences, albeit the correlation with Openness was slightly higher. Consequently, we decided to use negative attitudes to diversity as a single variable comprising all the items (alpha $=.89$; average inter-item $r=.25$ ). Table 1 reports item-level descriptive statistics and factor loadings (maximum likelihood estimation) for the Attitudes towards Diversity Scale. Items were rated on a scale: $1=$ very inaccurate, $2=$ moderately inaccurate, $3=$ neither accurate nor inaccurate, $4=$ moderately accurate, 5 $=$ very accurate. The scale was scored as the mean of items after any item reversal.

\subsubsection{Workplace Prejudice against Female workers, Ethnic Minority workers, Older Workers, and Workers with a Disability}

A set of 16 items were developed to measure prejudicial attitudes in the workplace towards women, ethnic minorities, older workers, and workers with a disability. Specifically, the four items for a given social group (e.g., female workers) asked whether that group is (a) less effective, (b) less productive, (c) causes more difficulties, or (d) causes no more difficulties (reversed) than the alternative group (e.g., male workers). Items were rated on a scale: $1=$ very inaccurate, $2=$ moderately inaccurate, $3=$ neither accurate nor inaccurate, $4=$ moderately accurate, $5=$ very accurate. Prejudice towards each of the four social groups was measured as the mean of the four items after reversing the "causes no more difficulties" item. Cronbach's alpha reliability was $.65, .80, .69$, and .73 for female, ethnic, older, and disability prejudice respectively. Average inter-item correlations were $.31, .50, .36$, and .40 for female, ethnic, older, and disability prejudice respectively. A set of confirmatory factor analysis models of these items are reported in the online supplement.

\subsubsection{Demographic indicators}

To mirror the social categories examined above, we created five binary variables to approximate category membership. These were all coded 0 for not in social group, and 1 for in the social group. These variables were gender identity (male $=0$, female $=1)$; English as a second language (no $\mathrm{ESL}=0, \mathrm{ESL}=1)$ and being foreign born $($ no $=0$, yes $=1)$ were both used as approximate indicators of being an ethnic minority in the Australian context; Older worker (aged under $55=0$, aged 55 or over $=1$; correlations for continuous age are provided in the online supplement); and disability status (no reported disability $=0$, reported disability $=1$ ).

\subsubsection{HEXACO Personality}

Personality traits were measured using the 200 -item version of the 
HEXACO Personality Inventory-Revised (Ashton, Lee, et al., 2014; Lee \& Ashton, 2004). Use of this long-form version of the HEXACO is particularly important for reliable facet-level measurement. The questionnaire measures 6 broad domains and 25 narrow facets. Each broad trait is defined by four narrow facets and there is one interstitial facet, altruism. Participants responded to items on a scale from $1=$ strongly disagree to $5=$ strongly agree. Scale scores were obtained as the mean of items after any necessary item reversal. Mean domain alpha reliability was .88 (range: .84, .90) and mean facet reliability was .76 (range: .64, .84) (see online supplement for details). Mean inter-item correlations were .19 (range: .14, .23) for domains and .29 (range: .18, .40) for facets.

\subsubsection{Values}

Schwartz's values were measured using the Portrait Value Questionnaire-PVQ 5X (Schwartz et al., 2012). The questionnaire includes 57 positively-keyed items which yield scores for 10 basic values. Each basic value is measured with between 3 and 9 items. Each item of the PVQ uses a third person perspective, where the statement describes the value of another person of the same gender as the participant (e.g., "it is important to her to have all sorts of new experiences"). Participants rate the importance to them of the value captured by the item from $1=$ opposed to my principles to $6=$ of great importance. When analyzing values, researchers need to make a choice about whether to ipsatize or not. We chose not to ipsatize because the focus of analyses was on the overall prediction of regression models. When scales are ipsatized, it is only possible to include nine of the 10 basic values as predictors in regression models, because the tenth is perfectly predicted by the other nine. However, we do present ipsatized values in the correlation matrix in the online supplement. We also computed two broad values of conservatism (versus Openness to change) and self-enhancement (versus self-transcendence), calculated as follows: conservatism $=($ tradition + conformity + security $)-$ (self-direction + stimulation); self-enhancement $=$ (hedonism + achievement + power) - (universalism + benevolence). This corresponds to the placement of these values on the two broadly orthogonal dimensions of Schwartz's values circumplex. It also corresponds broadly to the factor loadings obtained in Lee et al. (2009). Mean alpha reliability for the 10 basic scales was .75 (range: .50, .84) (see online supplement for details). Mean average inter-item correlations for the 10 basic scales was .40 (range: $.25, .64)$.

\subsubsection{Cognitive Ability}

Three tests were used to measure cognitive ability and overall intelligence. Abstract reasoning was measured using the 20-item ACER APTS test $($ alpha $=.68)$. Verbal reasoning was measured using the 34 item ACER ML (alpha = .81). Numerical reasoning was measured using the 34item ACER ML (alpha = .89) (Australian Council of Educational Research, 2003). The correlations between the three measures were 59 (numericalverbal), .56 (numerical-abstract), and .46 (verbal-abstract). Overall 
intelligence was measured by $z$-score standardizing the three tests, taking the sum, and $z$-score standardizing the sum.

\subsection{Data Analytic Approach}

In addition to reporting bivariate correlations, the overall and relative predictive validity of demographics, personality, values, and ability was assessed through a series of regression models. Regression models were estimated for each of the five outcome measures, although negative attitudes to diversity was the main outcome of interest. Models involving different predictor sets were considered to allow for a range of comparisons. In particular, each class of predictor was considered on its own (e.g., values, personality, intelligence). In addition, models with broad versus narrow predictors within a class were estimated separately. Overall predictive power was indexed using adjusted $r$-squared. It is essential to use adjusted $r$-squared as this provides an unbiased estimate of the variance explained in the population, using the population regression equation (Anglim \& Grant, 2014). Using adjusted $r$-squared is particularly important when comparing models with different numbers of predictors, such as when comparing models with $25 \mathrm{HEXACO}$ facet predictors to one with 6 HEXACO domain predictors. Confidence intervals on adjusted $r$-squared change was assessed using bootstrap double adjusted-r-squared confidence intervals (Anglim \& Grant, 2014).

In addition to reporting regression coefficients, we also report a dominance analysis. Dominance analysis partitions the overall r-squared of the model over the set of predictors and provides a fairer assessment of relative importance of each predictor when predictors are correlated (Tonidandel \& LeBreton, 2011). We used the "relaimpo" package in R (Grömping, 2006). For models with fewer than 18 predictors we used the "lmg" estimate that averages variance explained over predictor orderings. For models with 18 or more predictors we used the computationally tractable "car" estimate (Zuber \& Strimmer, 2011).

Because the sample size is relatively large, correlations were estimated with a relatively high degree of precision. For instance, the standard error of correlations was $0.036,0.034,0.027$, and 0.016 for correlations of $0, .25, .50$, and .75 respectively. Thus, we focus interpretation on the key patterns, which are almost all highly significant $(p<.001)$. We used the paired. $r$ function from the psych package to compare correlations (Revelle, 2018).

\section{Results}

\subsection{Descriptive Statistics and Correlations}

Descriptive statistics and the complete correlation matrix for demographics, personality, values (including raw and ipsatized), cognitive ability, and outcomes is presented in the online supplement. Table 2 presents descriptive statistics and correlations between the outcome measures. The strong correlations are consistent with negative attitudes to 
diversity and workplace prejudice representing a broader dimension. In general, the correlation between negative attitudes to diversity and prejudice towards specific groups of workers was significantly higher (all $p$-values $<.0001)$ for ethnicity $(r=.79)$ than for the other social groups $(r$ $=.57$ to .65$)$. In general, there was slightly more prejudice towards older workers and workers with a disability than towards female and ethnic workers $(d=0.20, p<.001)$.

Table 3 presents the correlations between demographics and broad predictors (i.e., intelligence, HEXACO domains, and broad values). Consistent with the proposed categories, self-enhancement had a strong negative correlation with Honesty-Humility $(r=-.60)$, and conservatism was moderately correlated with Openness $(r=-.24)$, although conservatism also showed moderate correlations with Conscientiousness, Agreeableness, and a negative correlation with intelligence. Demographic differences in ability, personality, and values were generally small. Females were higher on Emotionality $(r=.23)$, ESL participants reported higher levels of Conscientiousness $(r=.18)$, conservatism $(r=.19)$ and lower performance in the cognitive ability test $(r=-.16)$, and people aged over 55 reported lower levels of Conscientiousness $(r=-.15)$ and selfenhancement values $(r=-.17)$.

Table 4 shows the correlations between demographics and the broad predictors with attitudes to workplace diversity. In general, lower levels of intelligence were associated with negative attitudes to diversity $(r$ $=-.24$, supporting Hypothesis 5). For personality, Honesty-Humility $(r=-$ .24 , supporting Hypothesis 1$)$ Extraversion $(r=-.22)$ and Openness $(r=-$ .22 , supporting Hypothesis 3 ) all had significant negative correlations ( $p<$ $.001)$ with negative attitudes to diversity. The values of both conservatism $(r=.27$, supporting Hypothesis 4$)$ and self-enhancement $(r=.15$, supporting Hypothesis 2) were associated with greater levels of negative attitudes to diversity. Interestingly, the correlations between demographics and negative attitudes to diversity were low. Although the correlations were small, females showed less prejudice towards female workers $(r=-.15)$, and older people showed less prejudice towards older workers $(r=-.12)$. Focusing on other differences, the correlation between agreeableness and disability prejudice was significantly larger than those for other outcomes variables ( $p$-values of difference ranged from.01 to .0004).

Table 5 presents correlations of narrow predictors with attitudes to diversity. In several cases, the correlation with the narrow predictor was substantially larger than the corresponding broad predictor. For instance, verbal ability had a significantly larger negative correlation with negative attitudes to diversity than the other two ability measures (both significance tests comparing correlations were $p<.0002$ ). Modesty, Social self-esteem, and Altruism stood out as strong HEXACO facet predictors. Residualized correlations of attitudes to diversity with personality facets after overlap with the 6 HEXACO domains is removed are reported in the online supplement. These residualized correlations suggested that after 
controlling for overall Honesty-Humility (and the other personality domains), Modesty was related to less negative attitudes whereas Fairness was related to more negative attitudes. The residual correlation for Social self-esteem was statistically significant and suggested that it incrementally predicted less negative attitudes. The values of power, security, and tradition showed moderate positive correlations, and universalism showed a moderate negative correlation with negative attitudes.

\subsection{Regression Models Predicting Workplace Prejudice}

Table 6 presents the adjusted $r$-squared values for regression models predicting each outcome variable from various predictor sets. Regression coefficients and dominance analysis for all models are provided in the online supplement. It should be noted that demographics yielded only modest prediction and the prediction of the substantive models generally changed little with the inclusion of demographics. We focus our interpretation on the prediction of negative attitudes to diversity. First, inclusion of narrow traits improved prediction: personality went from .129 (6 factors) to .167 (25 facets) $\Delta \rho^{2}=.038(95 \%$ CI $[.008, .076]), F(19,705)$ $=2.73, p<.001$; values went from .099 ( 2 broad dimensions) to .197 (10 basic values), $\Delta \rho^{2}=.098(95 \%$ CI $[.058, .142]), \mathrm{F}(8,720)=12.10, p<$ .001 ; and cognitive ability went from .057 (overall IQ) to .084 (3 abilities) $, \Delta \rho^{2}=.027(95 \%$ CI $[.006, .054]), F(2,727)=11.78, p<.001$. This was most prominent in the case of the 10 narrow values. Second, adding values to a model with HEXACO and the three ability measures notably improved adjusted $r$-squared from .181 to .265. Finally, substituting facets for domains in a model with HEXACO, three abilities and 10 values improved prediction only modestly from .265 to .278 .

Table 7 presents the standardized coefficients and dominance weights for the model with the nine broad traits as predictors. In this combined model, negative attitudes was predicted by lower intelligence, Honesty-Humility, Emotionality, and Extraversion, and greater conservatism. In contrast to the zero-order correlations, Openness and selfenhancement were no longer significant predictors, and Emotionality became a significant predictor. Dominance analysis suggested that conservatism was the most important predictor followed by intelligence, Honesty-Humility and Extraversion. The emergence of Emotionality as a significant coefficient is presumably caused by removing some of the negative affect variance shared with Extraversion and other factors and leaving a more pure measure of the facets related to dependence and sentimentality. It should also be noted from the predictor correlations shown in Table 3 that several predictors were correlated in expected ways and may inform differences between zero-order correlations and regression coefficients. For example, self-enhancement correlated highly with Honesty-Humility $(r=-.56)$ and Openness correlated moderately with intelligence $(r=.15)$ and conservatism $(r=-.28)$. 


\section{Discussion}

The current study examined the predictive validity of HEXACO personality, values, and cognitive ability on employee attitudes to workplace diversity. Several important findings emerged. First, the HEXACO model of personality predicted negative attitudes to workplace diversity well. As expected, Honesty-Humility and Openness predicted less negative attitudes to workplace diversity. Extraversion also emerged as a good predictor. Second, Schwartz's values aligned with conservatism and self-enhancement provided the best set of predictors of negative attitudes to diversity. In particular, valuing power, security, and tradition, and not valuing universalism predicted negative attitudes to diversity. Third, higher cognitive ability, and verbal ability in particular, was associated with lower levels of negative attitudes to diversity. Fourth, narrow representations of personality and cognitive ability provided modest but meaningful incremental prediction of negative attitudes to diversity. Finally, consistent with strong correlations between negative attitudes to workplace diversity and prejudice towards specific categories of workers (e.g., females, ethnic, older, those with a disability), the pattern of predictor correlations were similar across outcome measures. Collectively, these findings supported the proposed model of three major categories of individual differences predicting negative attitudes to workplace diversity. The strong prediction by HEXACO Extraversion, and the facet of Social self-esteem in particular, further suggested a fourth major category of individual differences, potentially related to ego-threat. Detailed examination of the results provides a more nuanced understanding of the mapping of individual differences on negative attitudes to workplace diversity.

\subsection{Negative Attitudes to Diversity}

It is worth first considering how many workers were prejudiced or hostile to workplace diversity initiatives. In general, the level of agreement with items reflecting overt prejudice towards specific groups of workers was less than $10 \%$ and often less than $5 \%$. Furthermore, for some items, it is possible to construe a non-prejudicial interpretation to item agreement. For example, while $19 \%$ of participants felt that "some of the women [they] work with need to be more assertive to be effective supervisors", it may be that some of these participants are making a statement about the specific people at their workplace or would agree to equivalent statements about male workers. More common was workers indicating that they "neither agree nor disagree" that female or ethnic workers are less effective. For many such statements, endorsement of the neutral response was around $20 \%$. However, the meaning of this neutral response is less clear. It may indicate that such people see the relative effectiveness of social groups as an empirical question for which they do not know the answer. Or they may see disagreement with such statements as affirming the opposite, where for example they interpret disagreeing that women are less effective as 
implying that women are more effective. In summary, much of the variance in attitudes to diversity is captured by the variance in the degree of rejection of negative attitudes to women and minorities.

In general, we see the greatest divergence of opinion for the few items that address more pro-active beliefs about encouraging diversity. Specifically, only $31 \%$ believe that hiring more women and ethnic individuals would increase the creativity of the workforce. Presumably, the majority of people hold beliefs that either gender and ethnicity are unrelated to organizational effectiveness or that they are unable to evaluate that claim. Similarly, $60 \%$ believed that workers who are prejudiced have no place in an organization. These responses mirror current debates in Western societies about the degree to which employers should punish employees or job applicants who share prejudicial views outside work, often in the context of social media, but who are otherwise professional in their actions in the workplace.

\subsection{Individual Differences in Predicting Negative Attitudes to Diversity}

Social Dominance Traits. Consistent with the broader literature on prejudice, there was good support for the finding that self-enhancement values and low Honesty-Humility predicted negative attitudes to diversity. Self-enhancement and Honesty-Humility also exhibited a strong negative correlation $(r=-.60)$ suggesting that they captured similar predictive variance. Of all the values on the broad self-enhancement dimension, it was the negative correlation of universalism $(r=-.26)$ that best predicted negative attitudes to diversity, although valuing power was a modest predictor $(r=.13)$. When examining the facets of Honesty-Humility, it was modesty that had the strongest negative correlations with negative attitudes to diversity. These traits all align with a disposition and a value system that emphasizes self-interest and competition. It suggests that such workers are more willing to let the market, merit, and the prevailing social structures, prejudicial or otherwise, determine outcomes. They are likely to be less concerned with more progressive social justice issues.

Conservatism Traits. The findings showed that high conservatism and low Openness predicted negative attitudes to diversity. In particular, valuing tradition showed a particularly strong correlation, although the values of security and conformity were also significant. There are several explanations for this finding. First, embracing conventional values and traditional authority may be associated with the derogation of groups that may be perceived as subverting that traditional order. Individuals with a preference for strict and definite moral rules that explain how people should function in society may be more likely to display prejudice (Sibley \& Duckitt, 2008; Sibley et al., 2010). Second, they may be more inclined to adopt a set of beliefs that perceive differential outcomes across groups as natural. They may perceive attempts to pro-actively increase or support diversity in the workplace as running counter to treating each person on their merits and letting the natural order of things determine the outcomes. 
These findings regarding the importance of HEXACO Openness and Honesty-Humility are also consistent with the Big Five literature which suggests that Agreeableness and Openness are the strongest predictors of attitudes towards diversity (Duckitt, 2001; Ekehammar et al., 2004; Flynn, 2005; Hodson et al., 2009; Sibley \& Duckitt, 2008; Sibley et al., 2010). In general, the HEXACO model repartitions variance associated with Big Five Agreeableness and neuroticism into HEXACO HonestyHumility, Emotionality, and Agreeableness (Ashton, Lee, et al., 2014). It seems that Honesty-Humility likely captures some of the predictive validity of Agreeableness from the Big Five model. However, it is also likely to introduce variance of its own that captures traits related to the avoidance of prejudice. In one of the few differences between the prejudice measures, Agreeableness did appear more strongly negatively correlated with prejudice towards workers with a disability, which may link more closely with interpersonal than value-based forms of Agreeableness.

Low Cognitive Complexity Traits. Consistent with past research predicting general prejudice (Onraet et al., 2015), cognitive ability was negatively correlated with negative attitudes to workplace diversity. This correlation was larger for verbal ability than for abstract reasoning or numeric ability. More generally, education and intelligence are associated with liberal and progressive political values. For example, the correlation between intelligence and conservatism was -.28 in the current study. However, the regression coefficient for intelligence was still noteworthy after controlling for personality and the broad values that included conservatism.

Several explanations can be offered for this finding. First, intelligence, and verbal ability in particular, may enable workers to have greater sensitivity when statements, beliefs, and attitudes exhibit prejudicial content. Second, intelligence is correlated with tertiary education and professional careers which may lead to greater exposure to pro-diversity related perspectives. For example, Brandt and Crawford (2016) found that the correlation between cognitive ability and prejudice varied based on the focal group, with negative correlations emerging for prejudice towards traditionally disadvantaged groups like blacks and Hispanics and positive correlations with prejudice towards groups associated more with right-wing conservatism, such as fundamentalist Christians, conservatives, and big business. Third, the correlations between intelligence, Openness, and liberal political views may further lead workers to support more progressive views on diversity. Finally, cognitive ability may allow for greater tolerance of ambiguity and less need for closure, which may reduce reliance on negative stereotypes towards minorities.

Ego-Threat. A fourth category of individual differences that emerged from the results was the prediction by HEXACO Extraversion and social-self-esteem in particular. Compared to Big Five Extraversion, HEXACO Extraversion appears to contain somewhat more well-being, 
social effectiveness, and reversed neuroticism (Gaughan, Miller, \& Lynam, 2012) which manifests in stronger correlations with well-being (Aghababaei \& Arji, 2014) and trait emotional intelligence (Veselka, Just, Jang, Johnson, \& Vernon, 2012). The facet of Social self-esteem captures the degree to which a person feels that he or she is a worthwhile person who is valued by others. Some research has suggested that a lack of social skills and emotional intelligence may lead to projecting frustration and disapproval onto other social groups (Fein \& Spencer, 1997; Onraet, Van Hiel, De Keersmaecker, \& Fontaine, 2017), a trait that is correlated highly with HEXACO Extraversion (Veselka et al., 2012). Thus, one explanation for this finding is that workers who are insecure in their position in society may project this negativity onto minorities. Nonetheless, this finding has rarely been highlighted in research on general social prejudice, so more research is needed to assess the robustness and meaning of this finding.

Demographics. When considering the above findings, it is also worth noting that demographics were generally poor predictors of negative attitudes to workplace diversity. There was a small alignment whereby females had less prejudice towards female workers and older adults had less prejudice towards older workers. Similarly, people who spoke English as a second language or were foreign born also had slightly more negative attitudes to diversity. Nonetheless, overall, the results suggest that negative attitudes to diversity are much better explained by worker's fundamental traits and values than whether they belong to a particular social category.

\subsection{Optimal Prediction: Broad and Narrow Traits}

The current research also sought to assess the degree to which personality, values, and cognitive ability could be combined to predict negative attitudes to diversity and the degree to which narrow traits provide incremental prediction. In general, narrow measures led to meaningful incremental prediction for cognitive ability, personality, and values. First, incremental prediction by personality facets appeared to result from the combination of many subtle facet-level effects. For example, after controlling for the HEXACO domains, the facets of Fairness and Organization predicted more negative attitudes to diversity, whereas the facet of patience predicted less negative attitudes. Second, while the broad values of conservatism and self-enhancement were related to negative attitudes to diversity, the specific values provided superior prediction. For instance, the self-transcendence value of benevolence, which often reflects concern for family and friends, was only weakly related to negative attitudes to diversity. In contrast, the value of universalism, which reflects a more global concern for humanity that transcends the in-group-out-group distinction, was a strong predictor of lower levels of negative attitudes to diversity. Third, the incremental prediction of cognitive ability can be attributed to the greater importance of verbal ability.

Overall, personality, values, and cognitive ability each provided unique predictive validity of negative attitudes to diversity. Predictive validity was slightly higher for Schwartz's values than HEXACO 
personality, and this was achieved with a measure with only 57 items compared to the HEXACO's 200. This may suggest that values may be more proximal causes of attitudes to workplace issues that connect with political and moral orientations. Furthermore, incremental prediction of Schwartz's values may have been greater had a Big Five inventory been used given the particularly strong overlap between Honesty-Humility and values (Anglim, Knowles, et al., 2017). More generally, regression models that combined personality, values, and cognitive ability did achieve meaningful increments in predictive validity.

\subsection{Practical Implications}

While research on organizational and societal factors driving prejudice, discrimination and mistreatment at work is important (e.g., Köhler, González-Morales, Sojo, \& Olsen, 2018; O'Neil, Sojo, Fileborn, Scovelle, \& Milner, 2018), the individual differences perspective adopted in the current study also has several important practical implications. First, findings have implications for recruitment. The psychometric indicators of workplace prejudice overlap with those predicting some forms of counterproductive work behaviour (e.g., honesty-humility, conscientiousness, etc.) and job performance (e.g., cognitive ability). Thus, the present results show how psychometric assessment of prospective hires can provide additional insights about an applicant's likely attitudes to diversity in the workplace.

Second, findings may inform remediation at the individual level. Increasingly organizations, when faced with negative performance or behaviours from an employee, will use psychometric assessment to find out why. If an employee has significant cognitive ability or personality indicators that underpin these negative behaviours, such as intolerance, then this may suggest that remediation will be more difficult (e.g., Kulik, Pepper, Roberson, \& Parker, 2007). It may also need to take a different form than if these psychometric indicators are not present, especially given concerns about the efficacy of standard diversity training programs (e.g., Jones, King, Nelson, Geller, \& Bowes-Sperry, 2013; King, Gulick, \& Avery, 2010). If no psychometric indicators are present, for instance, positive behaviour change might be achieved through education and guidance. If the psychometric indicators are present then it may require a more intense form of coaching, involving a focus on self-awareness and self-regulation, as the motivators of the negative behaviours can be considered to be more intrinsic and internally motivated.

Third, findings have implications for remediation at the group level. If it becomes known that a group of employees are showing low levels of inclusion it may be worthwhile to find out if the workgroup has intrinsic psychometric characteristics inclining it toward these behaviours. Organisations can psychometrically assess entire workgroups in order to see if there are group-level indicators of traits related to intolerance. The current results provide guidance regarding what to look for. 


\subsection{Limitations and Future Research}

Several limitations should be noted. First, levels of endorsement of statements reflecting negative attitudes to diversity were relatively low. It is likely that the observed correlations would be stronger in social contexts where there is more variance in beliefs. Second, although prejudicial attitudes were measured in a confidential low-stakes research setting, social desirability may still lead some people to distort their honest responses. That said, results suggest that any tendency to respond in a more socially desirable way in a job applicant setting does not carry-over to the followup confidential surveys (Anglim, Lievens, Everton, Grant, \& Marty, 2018). Third, the measures of workplace prejudice were worded relatively directly. Future research should also explore more indirect and subtle forms of prejudice such as responses to vignette studies around CV selection, promotion decision-making, project allocation, and workplace requests (Telwatte, Anglim, Wynton, \& Moulding, 2017). Similarly, future research should seek to obtain measures of attitudes to workplace diversity using well-acquainted informants such as spouses, close friends, and family members. Future work could also seek to refine measures of attitudes to diversity that better capture the multidimensional structure of such attitudes by for example measuring attitudes to specific diversity related policies (e.g., quotas, affirmative action, sexual harassment policies, parental leave policies, etc.). Finally, future research could examine additional social categories of workers such as sexual orientation, gender identity, religious affiliation, and political orientation.

\subsection{Conclusion}

Overall, this study provides the first comprehensive estimate of the relative importance of broad and narrow measures of personality, values, and cognitive ability in predicting negative employee attitudes to workplace diversity. The current study had several strengths. First, the assessment of broad and narrow characteristics of personality, values, and cognitive ability using full-length measures in a large community sample of working adults, arguably makes this the most comprehensive assessment of the role of individual differences in predicting attitudes to workplace diversity, to date. Second, we hope that the model of four categories of individual differences provides a useful synthesizing framework for conceptualizing the effects of individual differences on negative attitudes to workplace diversity. Third, given the assessment context, the findings should generalize well for practitioners interested in predictive validities of psychometric tests used in selection settings, which are then used to predict subsequent attitudes in the workplace. Finally, the study adds further support for the benefits of measuring Honesty-Humility in workplace settings. These results can help organizations achieve their diversity goals by informing selection, training, and performance management, and ultimately improve harmony and respectful relations at work. 


\section{Open Practices Statement}

Data, data analysis scripts, supplementary materials, and item-level information is provided at https://osf.io/xdfq 8 


\section{References}

Ackerman, P. L., \& Heggestad, E. D. (1997). Intelligence, personality, and interests: Evidence for overlapping traits. Psychological Bulletin, 121, 219-245.

Adorno, T. W., Frenkel-Brunswik, E., Levinson, D. J., \& Stanford, N. R. (1950). The authoritarian personality. New York: Harper \& Brothers.

Aghababaei, N., \& Arji, A. (2014). Well-being and the HEXACO model of personality. Personality and Individual Differences, $56,139-142$.

Allport, G. W. (1954). The nature of prejudice. Oxford, England: Addison-Wesley.

Anglim, J., Bozic, S., Little, J., \& Lievens, F. (2018). Response distortion on personality tests in applicants: comparing high-stakes to low-stakes medical settings. Advances in Health Sciences Education, 23, 311-321.

Anglim, J., \& Grant, S. L. (2014). Incremental criterion prediction of personality facets over factors: Obtaining unbiased estimates and confidence intervals. Journal of Research in Personality, 53, 148-157.

Anglim, J., \& Grant, S. L. (2016). Predicting psychological and subjective well-being from personality: Incremental prediction from 30 facets over the big 5. Journal of Happiness Studies, 17, 59-80.

Anglim, J., Knowles, E. R., Dunlop, P. D., \& Marty, A. (2017). HEXACO Personality and Schwartz's Personal Values: A FacetLevel Analysis. Journal of Research in Personality, 68, 23-31.

Anglim, J., Lievens, F., Everton, L., Grant, S. L., \& Marty, A. (2018). HEXACO personality predicts counterproductive work behavior and organizational citizenship behavior in low-stakes and job applicant contexts. Journal of Research in Personality, 77, 11-20.

Anglim, J., Morse, G., De Vries, R. E., MacCann, C., \& Marty, A. (2017). Comparing Job Applicants to Non-Applicants Using an Item-Level Bifactor Model on the HEXACO Personality Inventory. European Journal of Personality, 31, 669-684.

Anglim, J., Morse, G., Dunlop, P. D., Minbashian, A., \& Marty, A. (2019). Predicting trait emotional intelligence from HEXACO personality: Domains, facets, and the general factor of personality. Journal of Personality.

Anglim, J., \& O'Connor, P. (2019). Measurement and research using the Big Five, HEXACO, and narrow traits: A primer for researchers and practitioners. Australian Journal of Psychology, 71, 16-25.

Ashkanasy, N. M., Härtel, C. E. J., \& Daus, C. S. (2002). Diversity and emotion: The new frontiers in organizational behavioral research. Journal of Management, 28, 307-338.

Ashton, M. C. (1998). Personality and job performance: The importance of narrow traits. Journal of Organizational Behavior, 19, 289-303.

Ashton, M. C., Lee, K., \& De Vries, R. E. (2014). The HEXACO honesty-humility, agreeableness, and emotionality factors a review of research and theory. Personality and Social Psychology Review, 18, 139-152.

Ashton, M. C., Lee, K., Goldberg, L. R., \& De Vries, R. E. (2009). Higher order factors of personality: Do they exist? Personality and Social Psychology Review, 13, 79-91.

Ashton, M. C., Lee, K., Perugini, M., Szarota, P., De Vries, R. E., Di Blas, L., . . De Raad, B. (2004). A six-factor structure of personality-descriptive adjectives: solutions from psycholexical studies in seven languages. Journal of Personality and Social Psychology, 86, 356-366.

Ashton, M. C., Paunonen, S. V., \& Lee, K. (2014). On the validity of narrow and broad personality traits: A response to. Personality and Individual Differences, 56, 24-28.

Australian Bureau of Statistics. (2017). 3412.0 - Migration, Australia, 2015-16. Retrieved from http://www.abs.gov.au/ausstats/abs@.nsf/mf/3412.0

Australian Council of Educational Research. (2003). ACER Select Manual. Melbourne, Victoria, Australia: ACER Press.

Avery, D. R., \& McKay, P. F. (2006). Target practice: An organizational impression management approach to attracting minority and female job applicants. Personnel Psychology, 59, 157-187.

Bergh, R., \& Akrami, N. (2016). Are non-agreeable individuals prejudiced? Comparing different conceptualizations of agreeableness. Personality and Individual Differences, 101, 153-159.

Brandt, M. J., \& Crawford, J. T. (2016). Answering unresolved questions about the relationship between cognitive ability and prejudice. Social Psychological and Personality Science, 7, 884-892.

Burkard, A. W., Boticki, M. A., \& Madson, M. B. (2002). Workplace discrimination, prejudice, and diversity measurement: A review of instrumentation. Journal of Career Assessment, 10, 343-361.

Byars-Winston, A., Fouad, N., \& Wen, Y. (2015). Race/ethnicity and sex in U.S. occupations, 1970-2010: Implications for research, practice, and policy. Journal of Vocational Behavior, 87, 54-70.

Christiansen, N. D., \& Robie, C. (2011). Further consideration of the use of narrow trait scales. Canadian Journal of Behavioural Science, 43, 183-194.

Colella, A., Hebl, M., \& King, E. (2017). One hundred years of discrimination research in the Journal of Applied Psychology: A sobering synopsis. Journal of Applied Psychology, 102, 500.

Costa, J. P. T., \& McCrae, R. R. (1992). Four ways five factors are basic. Personality and Individual Differences, 13, 653-665.

De Judicibus, M., \& McCabe, M. P. (2001). Blaming the target of sexual harassment: Impact of gender role, sexist attitudes, and work role. Sex Roles, 44, 401-417.

De Meuse, K. P., \& Hostager, T. J. (2001). Developing an instrument for measuring attitudes toward and perceptions of workplace diversity: An initial report. Human Resource Development Quarterly, 12, 33-51. 
De Raad, B., Barelds, D. P., Timmerman, M. E., De Roover, K., Mlačić, B., \& Church, A. T. (2014). Towards a pan-cultural personality structure: Input from 11 psycholexical studies. European Journal of Personality, 28, 497-510.

De Vries, R. E., \& Van Gelder, J.-L. (2015). Explaining workplace delinquency: The role of Honesty-Humility, ethical culture, and employee surveillance. Personality and Individual Differences, 86, 112-116.

Deyoung, C. G., Quilty, L. C., Peterson, J. B., \& Gray, J. R. (2014). Openness to experience, intellect, and cognitive ability. Journal of Personality Assessment, 96, 46-52.

Dick, P., \& Nadin, S. (2006). Reproducing gender inequalities? A critique of realist assumptions underpinning personnel selection research and practice. Journal of Occupational and Organizational Psychology, 79, 481-498.

Duckitt, J. (2001). A dual-process cognitive-motivational theory of ideology and prejudice. In M. P. Zanna \& M. P. Zanna (Eds.), Advances in experimental social psychology, Vol. 33. (pp. 41-113). San Diego, CA, US: Academic Press.

Eagly, A. H., \& Karau, S. J. (2002). Role congruity theory of prejudice toward female leaders. Psychological review, 109, 573598.

Ekehammar, B., Akrami, N., Gylje, M., \& Zakrisson, I. (2004). What matters most to prejudice: Big Five personality, Social Dominance Orientation, or Right-Wing Authoritarianism? European Journal of Personality, 18, 463-482.

Ely, R. J., \& Thomas, D. A. (2001). Cultural diversity at work: The effects of diversity perspectives on work group processes and outcomes. Administrative science quarterly, 46, 229-273.

Fein, S., \& Spencer, S. J. (1997). Prejudice as self-image maintenance: Affirming the self through derogating others. Journal of Personality and Social Psychology, 73, 31-44.

Fine, C. (2005). Delusions of gender: The real science behind sex differences: Icon Books Ltd.

Fine, C., \& Sojo, V. (2019). Women's value: beyond the business case for diversity and inclusion. Lancet, 393, $515-516$.

Fiske, S. T. (1998). Stereotyping, prejudice, and discrimination. The handbook of social psychology, 2, 357-411.

Fiske, S. T., \& Stevens, L. E. (1993). What's so special about sex? Gender stereotyping and discrimination: Sage Publications, Inc.

Flynn, F. J. (2005). Having an open mind: the impact of openness to experience on interracial attitudes and impression formation. Journal of Personality and Social Psychology, 88, 816-826.

Gaughan, E. T., Miller, J. D., \& Lynam, D. R. (2012). Examining the utility of general models of personality in the study of psychopathy: A comparison of the HEXACO-PI-R and NEO PI-R. Journal of personality disorders, 26, 513-523.

Goldman, B. M., Gutek, B. A., Stein, J. H., \& Lewis, K. (2006). Employment discrimination in organizations: Antecedents and consequences. Journal of Management, 32, 786-830.

Grömping, U. (2006). Relative importance for linear regression in R: the package relaimpo. Journal of Statistical Software, 17, 127.

Guillaume, Y. R. F., Dawson, J. F., Priola, V., Sacramento, C. A., Woods, S. A., Higson, H. E., . . West, M. A. (2014). Managing diversity in organizations: An integrative model and agenda for future research. European Journal of Work and Organizational Psychology, 23, 783-802.

Guillaume, Y. R. F., Dawson, J. F., Woods, S. A., Sacramento, C. A., \& West, M. A. (2013). Getting diversity at work to work: What we know and what we still don't know. Journal of Occupational and Organizational Psychology, 86, 123-141.

Harrison, D. A., \& Klein, K. J. (2007). What's the difference? Diversity constructs as separation, variety, or disparity in organizations. Academy of Management Review, 32, 1199-1228.

Harrison, D. A., Kravitz, D. A., Mayer, D. M., Leslie, L. M., \& Lev-Arey, D. (2006). Understanding attitudes toward affirmative action programs in employment: Summary and meta-analysis of 35 years of research. Journal of Applied Psychology, 91, 1013-1036.

Härtel, C. E. (2004). Towards a multicultural world: Identifying work systems, practices and employee attitudes that embrace diversity. Australian journal of management, 29, 189-200.

Heilman, M. E., \& Caleo, S. (2018). Combatting gender discrimination: A lack of fit framework. Group Processes \& Intergroup Relations, 21, 725-744.

Hodson, G., Book, A., Visser, B. A., Volk, A. A., Ashton, M. C., \& Lee, K. (2018). Is the Dark Triad common factor distinct from low Honesty-Humility? Journal of Research in Personality, 73, 123-129.

Hodson, G., \& Dhont, K. (2015). The person-based nature of prejudice: Individual difference predictors of intergroup negativity. European Review of Social Psychology, 26, 1-42.

Hodson, G., Hogg, S. M., \& MacInnis, C. C. (2009). The role of "dark personalities" (narcissism, Machiavellianism, psychopathy), Big Five personality factors, and ideology in explaining prejudice. Journal of Research in Personality, 43, 686-690.

Hough, L. M., \& Connelly, B. S. (2013). Personality measurement and use in industrial and organizational psychology. In K. F. Geisinger, B. A. Bracken, J. F. Carlson, J.-I. C. Hansen, N. R. Kuncel, S. P. Reise, \& M. C. Rodriguez (Eds.), APA handbook of testing and assessment in psychology, Vol. 1: Test theory and testing and assessment in industrial and organizational psychology (pp. 501-531). Washington, DC, US: American Psychological Association.

Jehn, K. A., Northcraft, G. B., \& Neale, M. A. (1999). Why differences make a difference: A field study of diversity, conflict and performance in workgroups. Administrative science quarterly, 44, 741-763.

Jones, K. P., King, E. B., Nelson, J., Geller, D. S., \& Bowes-Sperry, L. (2013). Beyond the business case: An ethical perspective of diversity training. Human Resource Management, 52, 55-74.

Jones, K. P., Peddie, C. I., Gilrane, V. L., King, E. B., \& Gray, A. L. (2016). Not so subtle: A meta-analytic investigation of the correlates of subtle and overt discrimination. Journal of Management, 42, 1588-1613.

Jones, O. (2017). Google's sexist memo has provided the alt-right with a new martyr. The Guardian: Australian edition. Retrieved from https://www.theguardian.com/commentisfree/2017/aug/08/google-sexist-memo-alt-right-martyr-james-damore 
Jonsen, K., Maznevski, M. L., \& Schneider, S. C. (2011). Special review article: Diversity and its not so diverse literature: An international perspective. International Journal of Cross Cultural Management, 11, 35-62.

Ju, S., Roberts, E., \& Zhang, D. (2013). Employer attitudes toward workers with disabilities: A review of research in the past decade. Journal of Vocational Rehabilitation, 38, 113-123.

King, E. B., Gulick, L. M., \& Avery, D. R. (2010). The divide between diversity training and diversity education: Integrating best practices. Journal of Management Education, 34, 891-906.

Kitrosser, H. (2016). Free Speech, Higher Education, and the PC Narrative. Minnesota Law Review, 101, 1987-20164.

Koenig, A. M., \& Eagly, A. H. (2014). Evidence for the social role theory of stereotype content: Observations of groups' roles shape stereotypes. Journal of Personality and Social Psychology, 107, 371-392.

Köhler, T., González-Morales, M. G., Sojo, V. E., \& Olsen, J. E. (2018). Who Is the Wolf and Who Is the Sheep? Toward a More Nuanced Understanding of Workplace Incivility. Industrial and organizational Psychology, 11, 122-129.

Kregel, J., \& Tomiyasu, Y. (1994). Employers' attitudes toward workers with disabilities: Effect of the americans with disabilities act. Journal of Vocational Rehabilitation, 4, 165-173.

Kulik, C. T., Pepper, M. B., Roberson, L., \& Parker, S. K. (2007). The rich get richer: Predicting participation in voluntary diversity training. Journal of Organizational Behavior: The International Journal of Industrial, Occupational and Organizational Psychology and Behavior, 28, 753-769.

Lee, K., \& Ashton, M. C. (2004). Psychometric properties of the HEXACO personality inventory. Multivariate Behavioral Research, 39, 329-358.

Lee, K., \& Ashton, M. C. (2014). The Dark Triad, the Big Five, and the HEXACO model. Personality and Individual Differences, $67,2-5$.

Lee, K., Ashton, M. C., Ogunfowora, B., Bourdage, J. S., \& Shin, K.-H. (2010a). The personality bases of socio-political attitudes: The role of Honesty-Humility and Openness to Experience. Journal of Research in Personality, 44, 115-119.

Lee, K., Ashton, M. C., Ogunfowora, B., Bourdage, J. S., \& Shin, K.-H. (2010b). The personality bases of socio-political attitudes: The role of Honesty-Humility and Openness to Experience. Journal of Research in Personality, 44, 115-119.

Lee, K., Ashton, M. C., Pozzebon, J. A., Visser, B. A., Bourdage, J. S., \& Ogunfowora, B. (2009). Similarity and assumed similarity in personality reports of well-acquainted persons. Journal of Personality and Social Psychology, 96, 460-472.

Lee, K., Ashton, M. C., Wiltshire, J., Bourdage, J. S., Visser, B. A., \& Gallucci, A. (2013). Sex, power, and money: Prediction from the Dark Triad and Honesty-Humility. European Journal of Personality, 27, 169-184.

Liu, J., Ludeke, S. G., \& Zettler, I. (2017). The HEXACO correlates of authoritarianism's facets in the US and Denmark. Personality and Individual Differences, 116, 348-352.

Marcus, B., Lee, K., \& Ashton, M. C. (2007). Personality dimensions explaining relationships between integrity tests and counterproductive behavior: Big Five, or one in addition? Personnel Psychology, 60, 1-34.

McAbee, S. T., Casillas, A., Way, J. D., \& Guo, F. (2019). The HEXACO Model in Education and Work. Zeitschrift für Psychologie, 227, 174-185.

Milliken, F. J., \& Martins, L. L. (1996). Searching for common threads: Understanding the multiple effects of diversity in organizational groups. Academy of Management Review, 21, 402-433.

Montei, M. S., Adams, G. A., \& Eggers, L. M. (1996). Validity of scores on the attitudes toward diversity scale (ATDS). Educational and Psychological Measurement, 56, 293-303.

Newman, A., Nielsen, I., Smyth, R., Hirst, G., \& Kennedy, S. (2018). The effects of diversity climate on the work attitudes of refugee employees: The mediating role of psychological capital and moderating role of ethnic identity. Journal of Vocational Behavior, 105, 147-158.

O'Neil, A., Sojo, V., Fileborn, B., Scovelle, A. J., \& Milner, A. (2018). The\# MeToo movement: an opportunity in public health? The Lancet, 391, 2587-2589.

O’Neill, T., Paunonen, S., Christiansen, N., \& Tett, R. (2013). Breadth in personality assessment: Implications for the understanding and prediction of work behavior. Handbook of personality at work, 299-332.

Oh, I. S., Lee, K., Ashton, M. C., \& De Vries, R. E. (2011). Are Dishonest Extraverts More Harmful than Dishonest Introverts? The Interaction Effects of Honesty-Humility and Extraversion in Predicting Workplace Deviance. Applied Psychology, 60, 496-516.

Ones, D. S., \& Viswesvaran, C. (1996). Bandwidth-fidelity dilemma in personality measurement for personnel selection. Journal of Organizational Behavior, 17, 609-626.

Onraet, E., Van Hiel, A., De Keersmaecker, J., \& Fontaine, J. R. (2017). The relationship of trait emotional intelligence with rightwing attitudes and subtle racial prejudice. Personality and Individual Differences, 110, 27-30.

Onraet, E., Van Hiel, A., Dhont, K., Hodson, G., Schittekatte, M., \& De Pauw, S. (2015). The Association of Cognitive Ability with Right-wing Ideological Attitudes and Prejudice: A Meta-analytic Review. European Journal of Personality, 29 , 599-621.

Parks-Leduc, L., Feldman, G., \& Bardi, A. (2015). Personality Traits and Personal Values A Meta-Analysis. Personality and Social Psychology Review, 19, 3-29.

Paunonen, S. V., \& Ashton, M. C. (2001). Big five factors and facets and the prediction of behavior. Journal of Personality and Social Psychology, 81, 524.

Paunonen, S. V., \& Jackson, D. N. (2000). What Is Beyond the Big Five? Plenty! Journal of Personality, 68, 821-835.

Pendry, L. F., Driscoll, D. M., \& Field, S. C. T. (2007). Diversity training: Putting theory into practice. Journal of Occupational and Organizational Psychology, 80, 27-50. 
Peterson, J. B. (2018). 12 rules for life: An antidote to chaos: Random House Canada.

Pletzer, J. L., Bentvelzen, M., Oostrom, J., \& De Vries, R. E. (2019). A meta-analysis of the relations between personality and workplace deviance: Big Five versus HEXACO. Journal of Vocational Behavior, 112, 369-383.

Pugh, S. D., Dietz, J., Brief, A. P., \& Wiley, J. W. (2008). Looking inside and out: The impact of employee and community demographic composition on organizational diversity climate. Journal of Applied Psychology, 93, 1422-1428.

Revelle, W. (2018). psych: Procedures for Personality and Psychological Research. Northwestern University, Evanston, Illinois, USA.

Roberts, V., Sojo, V., \& Grant, F. (2019). Organisational factors and non-accidental violence in sport: A systematic review. Sport Management Review.

Roets, A., \& van Hiel, A. (2011). Allport's prejudiced personality today: Need for closure as the motivated cognitive basis of prejudice. Current Directions in Psychological Science, 20, 349-354.

Rudman, L. A., Moss-Racusin, C. A., Phelan, J. E., \& Nauts, S. (2012). Status incongruity and backlash effects: Defending the gender hierarchy motivates prejudice against female leaders. Journal of Experimental Social Psychology, 48, 165-179.

Salgado, J. F., Moscoso, S., \& Berges, A. (2013). Conscientiousness, its facets, and the prediction of job performance ratings: Evidence against the narrow measures. International Journal of Selection and Assessment, 21, 74-84.

Saucier, G. (2009). Recurrent personality dimensions in inclusive lexical studies: Indications for a Big Six structure. Journal of Personality, 77, 1577-1614.

Schein, V. E., Mueller, R., Lituchy, T., \& Liu, J. (1996). Think manager-think male: A global phenomenon? Journal of Organizational Behavior, 17, 33-41.

Schneider, W. J., \& McGrew, K. S. (2012). The Cattell-Horn-Carroll model of intelligence.

Schwartz, S. H. (1992). Universals in the content and structure of values: Theoretical advances and empirical tests in 20 countries. Advances in experimental social psychology, 25, 1-65.

Schwartz, S. H., Cieciuch, J., Vecchione, M., Davidov, E., Fischer, R., Beierlein, C., . . Demirutku, K. (2012). Refining the theory of basic individual values. Journal of Personality and Social Psychology, 103, 663-688.

Sibley, C. G., \& Duckitt, J. (2008). Personality and prejudice: a meta-analysis and theoretical review. Personality And Social Psychology Review: An Official Journal Of The Society For Personality And Social Psychology, Inc, 12, 248-279.

Sibley, C. G., Harding, J. F., Perry, R., Asbrock, F., \& Duckitt, J. (2010). Personality and prejudice: Extension to the HEXACO personality model. European Journal of Personality, 24, 515-534.

Singh, B., Winkel, D. E., \& Selvarajan, T. T. (2013). Managing diversity at work: Does psychological safety hold the key to racial differences in employee performance? Journal of Occupational and Organizational Psychology, 86, 242-263.

Sojo, V. E., Wood, R. E., \& Genat, A. E. (2016). Harmful workplace experiences and women's occupational well-being: A metaanalysis. Psychology of Women Quarterly, 40, 10-40.

Sojo, V. E., Wood, R. E., Wood, S. A., \& Wheeler, M. A. (2016). Reporting requirements, targets, and quotas for women in leadership. The Leadership Quarterly, 27, 519-536.

Srivastava, S. (2013). Job satisfaction and organizational commitment relationship: Effect of personality variables. Vision: The Journal of Business Perspective, 17, 159-167.

Stratemeyer, M., Sojo Monzon, V., Wheeler, M., Rozenblat, V., Lee, I., Peter, D., . . Wood, R. (2018). Recruit Smarter-Technical Report. Retrieved from Melbourne, Australia:

Strauss, J. P., \& Connerley, M. L. (2003). Demographics, personality, contact, and universal-diverse orientation: An exploratory examination. Human Resource Management, 42, 159-174.

Strauss, J. P., Connerley, M. L., \& Ammermann, P. A. (2003). The 'threat hypothesis', personality, and attitudes toward diversity. Journal of Applied Behavioral Science, 39, 32-52.

Taylor, P., \& Walker, A. (1998). Employers and older workers: Attitudes and employment practices. Ageing and Society, 18, 641658.

Telwatte, A., Anglim, J., Wynton, S. K., \& Moulding, R. (2017). Workplace accommodations for employees with disabilities: A multilevel model of employer decision-making. Rehabilitation psychology, 62, 7-19.

Thompson, R. L., Brossart, D. F., Carlozzi, A. F., \& Miville, M. L. (2002). Five-factor model (Big Five) personality traits and universal-diverse orientation in counselor trainees. The Journal of psychology, 136, 561-572.

Tonidandel, S., \& LeBreton, J. M. (2011). Relative importance analysis: A useful supplement to regression analysis. Journal of Business and Psychology, 26, 1-9.

Ullman, S. E. (2010). Talking about sexual assault: Society's response to survivors: American Psychological Association.

Van Dalen, H. P., Henkens, K., \& Schippers, J. (2009). Dealing with older workers in Europe: A comparative survey of employers' attitudes and actions. Journal of European Social Policy, 19, 47-60.

Veselka, L., Just, C., Jang, K. L., Johnson, A. M., \& Vernon, P. A. (2012). The general factor of personality: A critical test. Personality and Individual Differences, 52, 261-264.

Wiersema, M., \& Mors, M. (2016). What board directors really think of gender quotas. Harvard Business Review, 14, 2-6.

Zuber, V., \& Strimmer, K. (2011). High-dimensional regression and variable selection using CAR scores. Statistical Applications in Genetics and Molecular Biology, 10, 1544-6115. 
Table 1

Item Statistics and Factor Loadings for Attitudes to Diversity Items

\begin{tabular}{|c|c|c|c|c|c|c|}
\hline \multirow{2}{*}{ Item } & \multirow[b]{2}{*}{$M$} & \multirow[b]{2}{*}{$S D$} & \multirow{2}{*}{$\begin{array}{l}\% \\
\mathrm{D}\end{array}$} & \multirow{2}{*}{$\begin{array}{l}\% \\
\mathrm{~N} \\
\end{array}$} & $\%$ & \multirow[b]{2}{*}{$r$} \\
\hline & & & & & A & \\
\hline \multicolumn{7}{|l|}{ Non-Reversed Items } \\
\hline 20. I find that ethnic workers seem to be less productive on average & 1.8 & 0.78 & .80 & .18 & .01 & .78 \\
\hline $\begin{array}{l}\text { 16. It seems that ethnic individuals in supervisory positions are ineffective } \\
\text { relative to other supervisors }\end{array}$ & 1.8 & 0.85 & .80 & .18 & .03 & .73 \\
\hline 12. Relative to male supervisors, female supervisors seem to be less effective & 1.8 & 0.81 & .81 & .17 & .02 & .71 \\
\hline 24. Sometimes I have to compensate for the lack of productivity of ethnic workers & 1.9 & 0.83 & .81 & .16 & .03 & .69 \\
\hline $\begin{array}{l}\text { 13. I would feel less comfortable with a female supervisor than I would with a } \\
\text { male supervisor }\end{array}$ & 1.9 & 0.88 & .78 & .19 & .04 & .66 \\
\hline $\begin{array}{l}\text { 25. Some of the workers in my previous organisations were only hired because } \\
\text { they were of an ethnic origin }\end{array}$ & 2.0 & 0.93 & .74 & .20 & .07 & .64 \\
\hline 23. I know some workers who would be fired if they were not of an ethnic origin & 1.8 & 0.81 & .82 & .16 & .02 & .63 \\
\hline $\begin{array}{l}\text { 10. The ethnic individuals in my organisation have a greater degree of difficulty } \\
\text { getting along with others }\end{array}$ & 2.1 & 0.86 & .69 & .27 & .04 & .58 \\
\hline 5. Under most circumstances, I would prefer a male supervisor & 2.4 & 0.93 & .50 & .43 & .07 & .56 \\
\hline $\begin{array}{l}\text { 14. Some of the members of my previous organisations were hired just because } \\
\text { they are women }\end{array}$ & 2.1 & 0.97 & .68 & .24 & .08 & .54 \\
\hline $\begin{array}{l}\text { 9. I feel that women have a more difficult time handling positions of authority } \\
\text { relative to men }\end{array}$ & 2.0 & 0.94 & .72 & .20 & .08 & .53 \\
\hline 19. The most qualified workers in my job seem to be male & 2.1 & 1.01 & .70 & .21 & .08 & .53 \\
\hline $\begin{array}{l}\text { 1. I have known many more qualified non ethnic individuals who should have } \\
\text { been hired instead of some of the ethnic individuals that have been hired } \\
\text { previously }\end{array}$ & 2.3 & 0.95 & .52 & .42 & .06 & .44 \\
\hline $\begin{array}{l}\text { 18. I have often picked up the slack for some of my female co-workers who are } \\
\text { less productive }\end{array}$ & 2.4 & 1.09 & .57 & .24 & .18 & .42 \\
\hline $\begin{array}{l}\text { 11. It seems as if some of the women I work with need to be more assertive to be } \\
\text { effective supervisors }\end{array}$ & 2.5 & 1.02 & .53 & .28 & .19 & .41 \\
\hline \multicolumn{7}{|l|}{ Reversed Items } \\
\hline $\begin{array}{l}\text { 2. We would have a more creative work environment if more women and ethnic } \\
\text { individuals were hired }\end{array}$ & 3.2 & 0.93 & .15 & .54 & .31 & -.17 \\
\hline 4. Workers who are prejudiced have no place in an organisation & 3.6 & 1.12 & .16 & .24 & .60 & -.19 \\
\hline $\begin{array}{l}\text { 7. If a member of my work group were prejudiced, he or she would be less likely } \\
\text { to fit in }\end{array}$ & 3.8 & 0.91 & .10 & .21 & .69 & -.24 \\
\hline $\begin{array}{l}\text { 8. If one of my co-workers were racist, I would confront that person and let him } \\
\text { or her know of my disapproval }\end{array}$ & 3.9 & 0.92 & .09 & .18 & .73 & -.30 \\
\hline 17. Most of the women in management positions do an outstanding job & 3.8 & 0.88 & .05 & .36 & .59 & -.38 \\
\hline 21. I do not feel comfortable with co-workers who are racist & 4.2 & 0.83 & .04 & .10 & .86 & -.38 \\
\hline $\begin{array}{l}\text { 3. All in all, I would say that ethnic workers are just as productive as other } \\
\text { workers }\end{array}$ & 4.3 & 0.88 & .03 & .11 & .85 & -.43 \\
\hline $\begin{array}{l}\text { 6. I feel that diversity is good for an organisation even if it means I will have a } \\
\text { supervisor who is of a different ethnic origin }\end{array}$ & 4.4 & 0.82 & .02 & .08 & .90 & -.44 \\
\hline $\begin{array}{l}\text { 22. I feel that increasing the hiring of women and ethnic individuals can only help } \\
\text { an organisation }\end{array}$ & 3.7 & 0.87 & .05 & .38 & .57 & -.46 \\
\hline $\begin{array}{l}\text { 26. I would feel just as comfortable with an ethnic supervisor as I do with a non } \\
\text { ethnic supervisor }\end{array}$ & 4.3 & 0.79 & .03 & .08 & .89 & -.60 \\
\hline $\begin{array}{l}\text { 15. Most of the ethnic supervisors in my organisation possess the same leadership } \\
\text { qualities as do those supervisors who are not }\end{array}$ & 4.0 & 0.86 & .04 & .24 & .72 & -.64 \\
\hline
\end{tabular}

Note. $\% \mathrm{D}$ is proportion disagree or strongly disagree; $\% \mathrm{~N}$ is proportion neither agree nor disagree; $\% \mathrm{~A}$ is proportion agree or strongly agree; $r$ is loading on first factor. 
Table 2

Descriptive Statistics and Correlations between Measures of Attitudes to Workplace Diversity

\begin{tabular}{lcccccc}
\hline \multicolumn{1}{c}{ Variable } & M & SD & 1 & 2 & 3 & 4 \\
\hline 1. Negative attitudes to diversity & 2.06 & 0.48 & & & & \\
2. Female prejudice & 1.81 & 0.65 & .62 & & & \\
3. Ethnic prejudice & 1.88 & 0.67 & .79 & .59 & & \\
4. Older prejudice & 1.97 & 0.64 & .57 & .52 & .63 & \\
5. Disability prejudice & 1.98 & 0.65 & .65 & .49 & .65 & .59 \\
\hline
\end{tabular}

Note. All correlations are significant at .001 . 
Table 3

Correlations between Demographics, and Broad Measures of Cognitive Ability, Personality, and Values

\begin{tabular}{|c|c|c|c|c|c|c|c|c|c|c|c|c|c|c|}
\hline Variable & 1 & 2 & 3 & 4 & 5 & 6 & 7 & 8 & 9 & 10 & 11 & 12 & 13 & 14 \\
\hline \multicolumn{15}{|l|}{ 1. Female } \\
\hline 2. ESL & -.09 & & & & & & & & & & & & & \\
\hline 3. Foreign born & -.12 & .47 & & & & & & & & & & & & \\
\hline 4. Aged $55+$ & -.07 & -.05 & .01 & & & & & & & & & & & \\
\hline 5. Disability & .04 & -.04 & -.05 & -.01 & & & & & & & & & & \\
\hline 6. Intelligence & -.11 & -.16 & -.13 & -.08 & .00 & & & & & & & & & \\
\hline 7. Honesty-Humility & .14 & -.10 & -.07 & .07 & .04 & -.02 & & & & & & & & \\
\hline 8. Emotionality & .23 & -.02 & -.05 & .04 & .01 & -.03 & -.07 & & & & & & & \\
\hline 9. Extraversion & -.01 & -.03 & -.03 & -.09 & .00 & .04 & .21 & -.22 & & & & & & \\
\hline 10. Agreeableness & -.02 & .09 & .03 & -.09 & .01 & -.09 & .41 & -.17 & .41 & & & & & \\
\hline 11. Conscientiousness & .06 & .18 & .03 & -.15 & .04 & -.12 & .28 & -.05 & .41 & .44 & & & & \\
\hline 12. Openness & -.04 & .07 & .07 & .04 & .00 & .15 & .10 & -.05 & .29 & .21 & .21 & & & \\
\hline 13. Conservatism & -.05 & .19 & .06 & .03 & -.04 & -.28 & .12 & .15 & -.04 & .25 & .28 & -.24 & & \\
\hline 14. Self-enhancement & -.06 & .09 & .03 & -.17 & -.06 & -.01 & -.60 & -.02 & .05 & -.28 & -.07 & -.12 & -.09 & \\
\hline Mean & 0.66 & 0.11 & 0.30 & 0.19 & 0.05 & 0.00 & 4.12 & 2.98 & 3.98 & 3.63 & 3.96 & 3.62 & 3.43 & 0.71 \\
\hline SD & 0.47 & 0.32 & 0.46 & 0.39 & 0.21 & 1.00 & 0.39 & 0.37 & 0.37 & 0.38 & 0.36 & 0.43 & 2.37 & 1.77 \\
\hline
\end{tabular}

Note. Female, ESL, Foreign born, Aged 55+, and Disability are all binary variables where 0 not the category, and 1 equals in category (e.g., male $=0$, female $=1$ ). ESL $=$ English as Second Language. Absolute correlations equal to or greater than .15 are bolded. Correlations equal to or greater than $.08, .10$, and .13 are significant at $.05, .01$, and .001 respectively. 
Table 4

Correlations of Demographics and Broad Measures of Cognitive Ability, Personality, and Values with Employee Attitudes to Workplace Diversity

\begin{tabular}{|c|c|c|c|c|c|}
\hline Variable & $\begin{array}{c}\text { Negative } \\
\text { Attitudes } \\
\text { to } \\
\text { Diversity }\end{array}$ & $\begin{array}{c}\text { Female } \\
\text { prejudice }\end{array}$ & $\begin{array}{c}\text { Ethnic } \\
\text { prejudice }\end{array}$ & $\begin{array}{c}\text { Older } \\
\text { prejudice }\end{array}$ & $\begin{array}{l}\text { Disability } \\
\text { prejudice }\end{array}$ \\
\hline \multicolumn{6}{|l|}{ Demographics } \\
\hline Female & -.09 & -.15 & -.11 & -.03 & -.12 \\
\hline ESL & .11 & .10 & .08 & .06 & .03 \\
\hline Foreign born & .10 & .05 & .04 & .02 & .03 \\
\hline Aged 55+ & .01 & .02 & .03 & -.12 & .03 \\
\hline Disability & .01 & .03 & .03 & .04 & .00 \\
\hline \multicolumn{6}{|l|}{ Cognitive Ability } \\
\hline Intelligence & -.24 & -.17 & -.18 & -.06 & -.07 \\
\hline \multicolumn{6}{|l|}{ Personality } \\
\hline Honesty-Humility & -.24 & -.16 & -.21 & -.21 & -.25 \\
\hline Emotionality & -.06 & -.06 & -.08 & -.06 & -.06 \\
\hline Extraversion & -.22 & -.08 & -.18 & -.17 & -.21 \\
\hline Agreeableness & -.08 & -.05 & -.08 & -.10 & -.19 \\
\hline Conscientiousness & -.05 & -.01 & -.08 & -.05 & -.11 \\
\hline Openness & -.22 & -.10 & -.12 & -.12 & -.15 \\
\hline \multicolumn{6}{|l|}{ Broad Values } \\
\hline Conservatism & .27 & .16 & .17 & .06 & .09 \\
\hline Self-enhancement & .15 & .12 & .12 & .18 & .15 \\
\hline
\end{tabular}

Note. Female, ESL, Foreign born, Aged 55+, and Disability are all binary variables where 0 equals not the category, and 1 equals in the category (e.g., male $=0$, female $=1$ ). ESL $=$ English as Second Language. Absolute correlations equal to or greater than .15 are bolded. Correlations equal to or greater than.08, .10, and .13 are significant at $.05, .01$, and .001 respectively. 
Table 5

Correlations of Narrow Measures of Cognitive Ability, Personality, and Values with Employee Attitudes to Workplace Diversity

\begin{tabular}{|c|c|c|c|c|c|}
\hline Variable & $\begin{array}{l}\text { Negative } \\
\text { Attitudes to } \\
\text { Diversity }\end{array}$ & $\begin{array}{c}\text { Female } \\
\text { prejudice }\end{array}$ & $\begin{array}{c}\text { Ethnic } \\
\text { prejudice }\end{array}$ & $\begin{array}{c}\text { Older } \\
\text { prejudice }\end{array}$ & $\begin{array}{l}\text { Disability } \\
\text { prejudice }\end{array}$ \\
\hline \multicolumn{6}{|l|}{ Cognitive Ability } \\
\hline Numerical ability & -.16 & -.08 & -.11 & -.01 & -.02 \\
\hline Verbal Ability & -.29 & -.23 & -.22 & -.17 & -.14 \\
\hline Abstract Ability & -.15 & -.11 & -.12 & .03 & -.01 \\
\hline \multicolumn{6}{|l|}{ Personality } \\
\hline H1: Sincerity & -.18 & -.08 & -.14 & -.12 & -.16 \\
\hline H2: Fairness & -.12 & -.08 & -.11 & -.11 & -.16 \\
\hline H3: Greed-Avoidance & -.19 & -.14 & -.15 & -.17 & -.22 \\
\hline H4: Modesty & -.25 & -.19 & -.25 & -.23 & -.25 \\
\hline E1: Fearfulness & .05 & .01 & .00 & .02 & .03 \\
\hline E2: Anxiety & .03 & .01 & .02 & .05 & .06 \\
\hline E3: Dependence & -.13 & -.09 & -.13 & -.11 & -.11 \\
\hline E4: Sentimentality & -.16 & -.11 & -.14 & -.15 & -.18 \\
\hline X1: Social Self-Esteem & -.22 & -.06 & -.20 & -.19 & -.21 \\
\hline X2: Social Boldness & -.15 & -.06 & -.13 & -.12 & -.13 \\
\hline X3: Sociability & -.17 & -.05 & -.14 & -.11 & -.16 \\
\hline X4: Liveliness & -.14 & -.06 & -.12 & -.13 & -.16 \\
\hline A1: Forgiveness & -.05 & -.03 & -.07 & -.06 & -.16 \\
\hline A2: Gentleness & -.02 & -.01 & -.03 & -.06 & -.11 \\
\hline A3: Flexibility & -.05 & -.05 & -.08 & -.07 & -.15 \\
\hline A4: Patience & -.13 & -.07 & -.09 & -.12 & -.16 \\
\hline C1: Organization & .05 & .06 & .01 & -.02 & -.03 \\
\hline C2: Diligence & -.09 & -.03 & -.09 & -.05 & -.12 \\
\hline C3: Perfectionism & -.04 & -.02 & -.06 & .00 & -.06 \\
\hline C4: Prudence & -.11 & -.05 & -.11 & -.10 & -.14 \\
\hline O1: Aesthetic Appreciation & -.19 & -.12 & -.12 & -.12 & -.17 \\
\hline O2: Inquisitiveness & -.18 & -.06 & -.11 & -.09 & -.10 \\
\hline O3: Creativity & -.13 & -.06 & -.07 & -.11 & -.11 \\
\hline O4: Unconventionality & -.16 & -.05 & -.08 & -.05 & -.05 \\
\hline I: Altruism & -.21 & -.14 & -.19 & -.20 & -.27 \\
\hline \multicolumn{6}{|l|}{ Values } \\
\hline Self-direction & .00 & .06 & .00 & .04 & -.01 \\
\hline Stimulation & -.05 & .01 & -.01 & .01 & -.06 \\
\hline Hedonism & -.01 & .04 & .00 & .02 & -.05 \\
\hline Achievement & .00 & -.01 & -.01 & .07 & -.02 \\
\hline Power & .13 & .10 & .12 & .12 & .15 \\
\hline Security & .16 & .12 & .10 & .02 & .01 \\
\hline Conformity & .11 & .08 & .08 & .06 & -.02 \\
\hline Tradition & .32 & .21 & .22 & .08 & .14 \\
\hline Benevolence & -.06 & -.01 & -.05 & -.10 & -.10 \\
\hline Universalism & -.26 & -.18 & -.18 & -.20 & -.27 \\
\hline
\end{tabular}

Note. Absolute correlations equal to or greater than. 15 are bolded. Correlations equal to or greater than $.08, .10$, and .13 are significant at $.05, .01$, and .001 respectively. 
Table 6

Adjusted R-Squared for Regression Models predicting Attitudes to Workplace Diversity from with Different Combinations of Personality, Values, and Cognitive Ability

\begin{tabular}{|c|c|c|c|c|c|c|c|}
\hline Predictor Set Name & Predictors & $k$ & $\begin{array}{l}\text { Negative } \\
\text { attitudes } \\
\text { to } \\
\text { diversity }\end{array}$ & $\begin{array}{c}\text { Female } \\
\text { prejudice }\end{array}$ & $\begin{array}{c}\text { Ethnic } \\
\text { prejudice }\end{array}$ & $\begin{array}{c}\text { Older } \\
\text { prejudice }\end{array}$ & $\begin{array}{l}\text { Disability } \\
\text { prejudice }\end{array}$ \\
\hline \multicolumn{8}{|l|}{ One-domain models } \\
\hline Demographics & Demog5 & 5 & .015 & .026 & .013 & .013 & .008 \\
\hline Ability broad & IQ & 1 & .057 & .027 & .030 & .002 & .004 \\
\hline Ability narrow & $\mathrm{CA} 3$ & 3 & .084 & .056 & .044 & .046 & .024 \\
\hline Personality broad & H6 & 6 & .129 & .035 & .080 & .073 & .105 \\
\hline Personality narrow & $\mathrm{H} 25$ & 25 & .167 & .043 & .103 & .089 & .118 \\
\hline Values broad & $\mathrm{V} 2$ & 2 & .099 & .040 & .045 & .035 & .031 \\
\hline Values narrow & V10 & 10 & .197 & .094 & .093 & .070 & .103 \\
\hline \multicolumn{8}{|l|}{ Composite Models } \\
\hline Broad & IQ, H6, V2 & 9 & .215 & .075 & .129 & .080 & .119 \\
\hline Ability-HEXACO & $\mathrm{CA} 3, \mathrm{H} 6$ & 9 & .181 & .079 & .113 & .106 & .122 \\
\hline HEXACO-Values & H6, V10 & 16 & .244 & .105 & .138 & .097 & .139 \\
\hline Mixed & CA3, H6, V10 & 19 & .265 & .128 & .151 & .121 & .151 \\
\hline Abilities-Facets & $\mathrm{CA} 3, \mathrm{H} 25$ & 28 & .198 & .077 & .123 & .117 & .132 \\
\hline Narrow & $\mathrm{CA} 3, \mathrm{H} 25, \mathrm{~V} 10$ & 38 & .278 & .123 & .158 & .124 & .156 \\
\hline
\end{tabular}

Note. $k=$ number of predictors. Predictor sets are as follows: Demog $5=$ Female, ESL, Foreign born, Aged 55+, Disability; IQ = intelligence; CA3 = 3 cognitive ability measures; H6 = 6 HEXACO domains; H25 = 25 HEXACO facets; V2 = two factors of values; V10 = 10 basic values. Bolded values are statistically significant $p<.05$. 
Table 7

Standardized Betas and Dominance Weights for Regression Models Predicting Attitudes to Workplace Diversity from Intelligence, Broad HEXACO Traits, and Broad Values.

\begin{tabular}{lccccc}
\hline & $\begin{array}{c}\text { Negative } \\
\text { Attitudes } \\
\text { to } \\
\text { Diversity }\end{array}$ & $\begin{array}{c}\text { Female } \\
\text { prejudice }\end{array}$ & $\begin{array}{c}\text { Ethnic } \\
\text { prejudice }\end{array}$ & $\begin{array}{c}\text { Older } \\
\text { prejudice }\end{array}$ & $\begin{array}{c}\text { Disability } \\
\text { prejudice }\end{array}$ \\
\hline Standardized Beta & & & & & \\
Intelligence & $-.16^{*}$ & $-.13^{*}$ & $-.13^{*}$ & -.02 & -.04 \\
Honesty-Humility & $-.21^{*}$ & $-.14^{*}$ & $-.18^{*}$ & $-.13^{*}$ & $-.20^{*}$ \\
Emotionality & $-.16^{*}$ & $-.11^{*}$ & $-.16^{*}$ & $-.11^{*}$ & $-.15^{*}$ \\
Extraversion & $-.17^{*}$ & -.05 & $-.15^{*}$ & $-.18^{*}$ & $-.15^{*}$ \\
Agreeableness & -.01 & -.04 & -.02 & .01 & $-.10^{*}$ \\
Conscientiousness & .00 & .01 & -.03 & .05 & .01 \\
Openness & -.06 & -.01 & .01 & -.04 & -.03 \\
Conservatism & $.26^{*}$ & $.16^{*}$ & $.19^{*}$ & .06 & $.14^{*}$ \\
Self-enhancement & .04 & .04 & .02 & $.12^{*}$ & .02 \\
Dominance Weight & & & & & .02 \\
Intelligence & .040 & .021 & .023 & .002 & .003 \\
Honesty-Humility & .039 & .018 & .030 & .024 & .038 \\
Emotionality & .015 & .008 & .016 & .008 & .013 \\
Extraversion & .031 & .003 & .023 & .024 & .025 \\
Agreeableness & .004 & .002 & .003 & .003 & .016 \\
Conscientiousness & .002 & .001 & .003 & .002 & .004 \\
Openness & .019 & .003 & .005 & .006 & .008 \\
Conservatism & .062 & .023 & .030 & .004 & .013 \\
Self-enhancement & .012 & .007 & .007 & .019 & .010 \\
\hline
\end{tabular}

$* p<.05$ 


\section{Social Dominance}

- Personality: Low honesty-humility (H1)

- Values: Self-enhancement (H2)

\section{Conservatism}

- Personality: Low openness $(\mathrm{H} 3)$

- Values: Conservatism (H4)

3. Low Cognitive Complexity

- Ability: Low intelligence (H5)

- Personality: Low openness (H3)
Negative Attitudes to Workplace Diversity

- General negative attitudes to workplace diversity

- Prejudice towards specific groups of workers: e.g.

- Female workers

- Ethnic minority workers

- Older workers

- Workers with disabilities

4. Ego-threat (exploratory finding)

- Personality: Low HEXACO extraversion

- Personality: Low social self-esteem

Figure 1. Four Categories of Individual Differences on Negative Attitudes to Workplace Diversity. Categories 1 to 3 were hypothesized a priori, and Category 4 was an exploratory finding. 


\section{Online Supplement}

Table S1

Cronbach's Alpha Reliabilities for Scales

\begin{tabular}{|c|c|c|}
\hline Scale & Alpha & $\begin{array}{l}\text { Average } \\
\text { Inter-Item } r\end{array}$ \\
\hline Honesty-humility & .90 & .21 \\
\hline Emotionality & .84 & .14 \\
\hline Extraversion & .90 & .23 \\
\hline Agreeableness & .88 & .18 \\
\hline Conscientiousness & .88 & .19 \\
\hline Openness & .89 & .20 \\
\hline H1: Sincerity & .73 & .25 \\
\hline H2: Fairness & .76 & .29 \\
\hline H3: Greed-Avoidance & .81 & .35 \\
\hline H4: Modesty & .77 & .30 \\
\hline E1: Fearfulness & .75 & .27 \\
\hline E2: Anxiety & .79 & .32 \\
\hline E3: Dependence & .72 & .25 \\
\hline E4: Sentimentality & .73 & .25 \\
\hline X1: Social Self-Esteem & .80 & .34 \\
\hline X2: Social Boldness & .80 & .34 \\
\hline X3: Sociability & .80 & .33 \\
\hline X4: Liveliness & .79 & .32 \\
\hline A1: Forgiveness & .80 & .33 \\
\hline A2: Gentleness & .69 & .22 \\
\hline A3: Flexibility & .64 & .18 \\
\hline A4: Patience & .78 & .30 \\
\hline $\mathrm{C} 1$ : Organization & .84 & .40 \\
\hline C2: Diligence & .73 & .25 \\
\hline C3: Perfectionism & .73 & .26 \\
\hline C4: Prudence & .76 & .29 \\
\hline O1: Aesthetic Appreciation & .82 & .36 \\
\hline $\mathrm{O} 2$ : Inquisitiveness & .79 & .31 \\
\hline O3: Creativity & .75 & .28 \\
\hline O4: Unconventionality & .67 & .20 \\
\hline I: Altruism & .75 & .27 \\
\hline Self-direction & .74 & .33 \\
\hline Stimulation & .71 & .45 \\
\hline Hedonism & .74 & .49 \\
\hline Achievement & .50 & .25 \\
\hline Power & .78 & .38 \\
\hline Security & .81 & .41 \\
\hline Conformity & .82 & .43 \\
\hline Tradition & .84 & .64 \\
\hline Benevolence & .72 & .30 \\
\hline Universalism & .82 & .33 \\
\hline Negative attitudes to diversity & .89 & .25 \\
\hline Female prejudice & .65 & .31 \\
\hline Ethnic prejudice & .85 & .65 \\
\hline Older prejudice & .69 & .36 \\
\hline Disability prejudice & .73 & .40 \\
\hline
\end{tabular}


Table S2

Correlations Between HEXACO Facets (after overlap with Six HEXACO Domains has Been Removed) and Attitudes to Workplace Diversity.

\begin{tabular}{|c|c|c|c|c|c|}
\hline Variable & $\begin{array}{l}\text { Negative } \\
\text { attitudes to } \\
\text { diversity }\end{array}$ & $\begin{array}{c}\text { Female } \\
\text { prejudice }\end{array}$ & $\begin{array}{c}\text { Ethnic } \\
\text { prejudice }\end{array}$ & $\begin{array}{c}\text { Older } \\
\text { prejudice }\end{array}$ & $\begin{array}{l}\text { Disability } \\
\text { prejudice }\end{array}$ \\
\hline H1: Sincerity & .00 & .05 & .02 & .05 & .04 \\
\hline H2: Fairness & .10 & .05 & .09 & .08 & .08 \\
\hline H3: Greed-Avoidance & -.01 & -.01 & .01 & -.02 & -.04 \\
\hline H4: Modesty & -.09 & -.09 & -.13 & -.11 & -.07 \\
\hline E1: Fearfulness & .07 & .04 & .04 & .04 & .06 \\
\hline E2: Anxiety & -.01 & .01 & .02 & .04 & .01 \\
\hline E3: Dependence & -.06 & -.04 & -.06 & -.05 & -.04 \\
\hline E4: Sentimentality & -.01 & -.02 & .00 & -.04 & -.04 \\
\hline X1: Social Self-Esteem & -.07 & .01 & -.08 & -.07 & -.06 \\
\hline X2: Social Boldness & .03 & -.02 & .02 & .01 & .04 \\
\hline X3: Sociability & -.01 & .01 & .01 & .03 & -.01 \\
\hline X4: Liveliness & .06 & .00 & .05 & .02 & .02 \\
\hline A1: Forgiveness & .01 & .01 & -.02 & .02 & -.03 \\
\hline A2: Gentleness & .04 & .04 & .05 & .01 & .04 \\
\hline A3: Flexibility & .04 & .01 & .01 & .03 & .00 \\
\hline A4: Patience & -.10 & -.05 & -.03 & -.06 & .00 \\
\hline C1: Organization & .11 & .09 & .09 & .01 & .05 \\
\hline C2: Diligence & -.03 & -.02 & -.02 & .01 & -.03 \\
\hline C3: Perfectionism & -.03 & -.03 & -.02 & .03 & .00 \\
\hline C4: Prudence & -.07 & -.04 & -.05 & -.06 & -.02 \\
\hline O1: Aesthetic Appreciation & .00 & -.05 & .00 & -.02 & -.06 \\
\hline $\mathrm{O} 2$ : Inquisitiveness & -.03 & .02 & -.03 & .00 & .01 \\
\hline O3: Creativity & .06 & .01 & .05 & -.02 & .02 \\
\hline O4: Unconventionality & -.03 & .02 & -.01 & .03 & .03 \\
\hline I: Altruism & -.03 & -.04 & -.03 & -.06 & -.08 \\
\hline
\end{tabular}

Note. Absolute correlations equal to or greater than.08 are bolded. Correlations equal to or greater than $.08, .10$, and .13 are significant at $.05, .01$, and .001 respectively. 


\subsection{Confirmatory Factor Analysis of Workplace Prejudice Items}

In order to examine the factor structure of the 16 item Workplace Prejudice items, we conducted confirmatory factor analysis. Specifically, the 16 items were designed such that 4 social categories (female, ethnic, older, disability) were crossed with 4 item types (less effective, less productive, more problems, no more problems). Thus, workplace prejudice towards each social category was measured using 4 items and each included the 4 question types. Note that the "no more problems" question type was reversed. We expected that items on this scale would be influenced by (a) a general workplace prejudice factor, (b) the social category (i.e., gender, ethnicity, older, disability), and (c) the item stem (i.e., more problems; less effective; less productive; no more problems). In particular, we expected the reversed stem of "no more problems" to induce a method effect because it is a reversed item. Overall, we felt that it was important to include a reversed item to control for acquiescence bias.

We estimated five confirmatory factor analytic models using maximum likelihood extraction. Model 0 had all items loading on one overall prejudice factor. Model 1 was a fourfactor model where each item loaded on the relevant social category and these factors were allowed to correlate. Building on Model 1, Model 2 posited that there was a higher-order model that explained the covariance between the four social category factors. Finally, Model 3, added a reversed-item factor to Model 2, where all reversed items had a common loading on a reversed item factor.

Fit measures are shown in Table S3 and standardized coefficients are shown in Table S4. Model 0 provides a baseline model. In general, it captures the general prejudice factor that pervades all the items. Model 1 models the four correlated social categories. This leads to a substantial improvement in fit suggesting that participants have somewhat different attitudes towards each social category. Equally, factor correlations between the social categories ranged from .63 to 82 consistent with the common workplace prejudice factor underlying these items. Model 2 explicitly models this as a higher-order factor. This is a more parsimonious model than Model 1 in that it represents the factor correlations in terms of a single global factor. The lack of any decline in model fit from Model 2 supports the idea that a single global factor explains the social category correlations. The loadings of factors on this category were fairly similar, although ethnicity (.95) loaded highest and gender loaded the lowest (.76). Model 3 incorporated the method effect associated with reversed items and this yielded a modest improvement in model fit.

Model 4 was a bifactor model where each item loaded both on a global factor and on its relevant substantive social category factor, where factors were constrained to be uncorrelated. Loadings on the global factor in Model 4 were very similar to those in Model 0. As is typical for bifactor models, loadings on the substantive factors (i.e., the four social categories) were weaker and a little less consistent than those seen in Model 1 (i.e., correlated 4 factor model). Nonetheless, there were still many substantive loadings consistent with each social category having a unique effect on responses.

Overall, these analyses suggest that the scale is operating as designed and as expected. 
Table S3 Fit Measures

\begin{tabular}{lrrrrr}
\hline Fit Measure & Model 0 & Model 1 & Model 2 & Model 3 & \multicolumn{1}{c}{ Model 4 } \\
\hline Chi-square & 989.0 & 577.5 & 584.2 & 404.0 & 412.9 \\
$d f$ & 104 & 98 & 100 & 98 & 88 \\
RMSEA & .108 & .082 & .081 & .065 & .071 \\
CFI & .820 & .903 & .902 & .938 & .934 \\
NNFI & .792 & .881 & .882 & .924 & .910 \\
TLI & .792 & .881 & .882 & .924 & .910 \\
\hline
\end{tabular}


Table S4

Standardized Coefficients for the CFA Models of Workplace Prejudice Items

\begin{tabular}{|c|c|c|c|c|c|}
\hline Coefficient & Model 0 & Model 1 & Model 2 & Model3 & Model4 \\
\hline \multicolumn{6}{|l|}{ Standardized Item Residual Variances } \\
\hline disability_less_effective $\sim$ disability_less_effective & .39 & .20 & .20 & .19 & .20 \\
\hline disability_less_productive $\sim$ disability_less_productive & .52 & .39 & .39 & .39 & .39 \\
\hline disability_more_problems $\sim \sim$ disability_more_problems & .83 & .79 & .79 & .79 & .78 \\
\hline disability_no_more_problems $\sim$ disability_no_more_problems & .79 & .77 & .77 & .59 & .77 \\
\hline ethnic_less_effective ethnic_less_effective & .38 & .31 & .32 & .32 & .35 \\
\hline ethnic_less_productive ethnic_less_productive & .36 & .29 & .28 & .28 & .10 \\
\hline ethnic_more_problems $\sim$ ethnic_more_problems & .46 & .43 & .43 & .43 & .44 \\
\hline ethnic_no_more_problems $\sim$ ethnic_no_more_problems & .77 & .77 & .77 & .57 & .76 \\
\hline female_less_effective $\sim$ female_less_effective & .78 & .54 & .53 & .48 & .08 \\
\hline female_less_productive female_less_productive & .78 & .57 & .55 & .51 & .55 \\
\hline female_more_problems $\sim$ female_more_problems & .61 & .54 & .55 & .59 & .58 \\
\hline female_no_more_problems $\sim$ female_no_more_problems & .89 & .87 & .88 & .75 & .88 \\
\hline older_less_effective $\sim$ older_less_effective & .84 & .82 & .81 & .81 & .82 \\
\hline older_less_productive $\sim$ older_less_productive & .45 & .30 & .31 & .30 & .31 \\
\hline older_more_problems $\sim$ older_more_problems & .47 & .33 & .33 & .33 & .32 \\
\hline older_no_more_problems $\sim$ older_no_more_problems & .83 & .83 & .83 & .64 & .82 \\
\hline \multicolumn{6}{|l|}{ Standardized Loadings } \\
\hline disability $=\sim$ disability_less_effective & & .90 & .89 & .90 & .48 \\
\hline disability $=\sim$ disability_less_productive & & .78 & .78 & .78 & .42 \\
\hline disability $=\sim$ disability_more_problems & & .46 & .46 & .46 & .28 \\
\hline disability $=\sim$ disability_no_more_problems & & -.48 & -.48 & -.37 & -.18 \\
\hline ethnic $=\sim$ ethnic_less_effective & & .83 & .83 & .83 & .17 \\
\hline ethnic $=\sim$ ethnic_less_productive & & .84 & .85 & .85 & .53 \\
\hline ethnic $=\sim$ ethnic_more_problems & & .75 & .75 & .75 & .09 \\
\hline ethnic $=\sim$ ethnic_no_more_problems & & -.48 & -.48 & -.37 & -.06 \\
\hline female $=\sim$ female_less_effective & & .68 & .69 & .72 & .86 \\
\hline female $=\sim$ female_less_productive & & .66 & .67 & .70 & .51 \\
\hline female $=\sim$ female_more_problems & & .68 & .67 & .64 & .15 \\
\hline female $=\sim$ female_no_more_problems & & -.36 & -.35 & -.25 & -.04 \\
\hline older $=\sim$ older_less_effective & & .43 & .43 & .43 & .23 \\
\hline older $=\sim$ older_less_productive & & .84 & .83 & .84 & .41 \\
\hline older $=\sim$ older_more_problems & & .82 & .82 & .82 & .43 \\
\hline older $=\sim$ older_no_more_problems & & -.42 & -.42 & -.31 & -.11 \\
\hline
\end{tabular}

Standardized Factor Variances 
ethnic ethnic

female $\sim$ female

older older

disability $\sim$ disability

Standardized Loadings on Global Factor

global $=\sim$ ethnic

global global

global $=\sim$ older

global $=\sim$ disability

global $=\sim$ female
1.00

1.00

1.00

1.00

$$
.11
$$$$
.43
$$$$
.23
$$

1.00

.88

.86

.76
.11

.49

.24

.27

.94

1.00

.87

.85

.72

\section{Standardized Item Loadings on Global Factor}

prejudice $=\sim$ disability_less_effective $\quad .78$

prejudice $=\sim$ disability_less_productive

prejudice $=\sim$ disability_more_problems

prejudice $=\sim$ disability_no_more_problems

prejudice $=\sim$ ethnic_less_effective

prejudice $=\sim$ ethnic_less_productive

prejudice $=\sim$ ethnic_more_problems

prejudice $=\sim$ ethnic_no_more_problems

prejudice $=\sim$ female_less_effective

prejudice $=\sim$ female_less_productive

prejudice $=\sim$ female_more_problems

prejudice $=\sim$ female_no_more_problems

prejudice $=\sim$ older_less_effective

prejudice $=\sim$ older_less_productive

prejudice $=\sim$ older_more_problems

prejudice $=\sim$ older_no_more_problems

\section{Global Factor Standardized Variance}

prejudice $\sim$ prejudice

1.00
1.00

1.00

1.00

1.00
.76

.66

.37

$-.45$

.79

.79

.75

$-.49$

.43

.44

.63

$-.35$

.36

.72

.71

$-.41$

\section{Factor Correlations}

ethnic $\sim$ female

ethnic $\sim$ older

disability ethnic

female $\sim$ older

disability female

disability older

\section{Loadings on Reversed Factor}

reversed $=\sim$ ethnic_no_more_problems

reversed $=\sim$ female_no_more_problems 
reversed $=\sim$ disability_no_more_problems 4.46

reversed $=\sim$ older_no_more_problems $\quad .45$

Reversed Standardized Variance and Correlation

reversed $\sim$ reversed

global reversed 